\title{
The Impact of Microcredit on the Poor in Bangladesh: Revisiting the Evidence
}

David Roodman and Jonathan Morduch

\begin{abstract}
We replicate and reanalyze the most influential study of microcredit impacts (Pitt and Khandker, 1998). That study was celebrated for showing that microcredit reduces poverty, a much hoped-for possibility (though one not confirmed by recent randomized controlled trials). We show that the original results on poverty reduction disappear after dropping outliers, or when using a robust linear estimator. Using a new program for estimation of mixed process maximum likelihood models, we show how assumptions critical for the original analysis, such as error normality, are contradicted by the data. We conclude that questions about impact cannot be answered in these data.
\end{abstract}

JEL Codes: C21, C23, C24, C25, O12, O16

Keywords: microcredit, bangladesh, poverty reduction

Forthcoming in the Journal of Development Studies 


\title{
The Impact of Microcredit on the Poor in Bangladesh: Revisiting the Evidence
}

\author{
David Roodman \\ Center for Global Development \\ Jonathan Morduch \\ New York University \\ Financial Access Initiative
}

June 2013 revision

We thank Mark Pitt for assistance with data and comments on earlier versions; Maren Duvendack and Richard Palmer-Jones for scrutiny of our data set construction; and Xavier Giné, Dean Karlan, and anonymous referees for reviews. Correspondence: droodman@gmail.com

CGD is grateful for contributions from the Australian Agency for International Development in support of this work.

David Roodman and Jonathan Morduch. 2009. "The Impact of Microcredit on the Poor in Bangladesh: Revisiting the Evidence.” CGD Working Paper 174. Washington, D.C.: Center for Global Development. http://www.cgdev.org/content/publications/ detail/1422654

Center for Global Development 1800 Massachusetts Ave., NW Washington, DC 20036

202.416 .4000

(f) 202.416 .4050
The Center for Global Development is an independent, nonprofit policy research organization dedicated to reducing global poverty and inequality and to making globalization work for the poor. Use and dissemination of this Working Paper is encouraged; however, reproduced copies may not be used for commercial purposes. Further usage is permitted under the terms of the Creative Commons License.

www.cgdev.org The views expressed in CGD Working Papers are those of the authors and should not be attributed to the board of directors or funders of the Center for Global Development. 
The Impact of Microcredit on the Poor in Bangladesh: Revisiting the Evidence

Over the last few decades, microcredit has captured millions of customers, billions of dollars in financing, a Nobel Prize, and the imagination of the global public. Many have seen microcredit as lifting families out of poverty, especially when lent to women. The movement owes its strength in part to an early literature based on observational data that shows strong positive impacts. The most prominent studies in this literature took place in the leading nation of microcredit, Bangladesh. More recently, muted results from randomized trials in India, the Philippines, and elsewhere are prompting second thoughts. ${ }^{1}$ The sharp contradiction between the old and new studies raises questions. Has the impact of microcredit varied over time and place? Is the key that the Bangladesh studies were longerterm? Or is the difference in methods?

Some of the questions cannot be answered without replicating studies and extending them to gauge robustness. Toward that goal, we revisit the most-cited evaluation of the impacts of microcredit, Pitt and Khandker (PK, 1998), which is based on a structural model that disaggregates impacts by gender and relies in part on assumptions akin to regression discontinuity design. The study is notable for its historical place in the literature, its long time frame, and its relevance to the continuing public controversy over the efficacy of microcredit. Grameen Bank founder Muhammad Yunus once regularly claimed, in an extrapolation from coefficient estimates in PK, that 'In a typical year 5 per cent of Grameen borrowers...rise above the poverty level. ${ }^{2} \mathrm{PK}$ remains the single most cited empirical study of microcredit, with 890 cites on Google Scholar as of June 17, 2013.

PK attacks selection bias through an innovative and complex limited-information maximum likelihood (LIML) framework. While questions have been raised about the robustness of results to alternative estimation methods (Morduch, 1998; Chemin, 2008; Duvendack and Palmer-Jones, 2012), Pitt (1999; 2012) has strongly defended PK against 
The Impact of Microcredit on the Poor in Bangladesh: Revisiting the Evidence

such criticisms. Our close replication of the original methods helps resolve several outstanding disputes.

We find several problems in PK. The PK finding that microcredit reduced poverty especially when given to women is robust to fixes for some but not all of these problems. A seemingly innocuous choice in imputation for the log of 0 in the borrowing variables leaves the effect sizes unidentified. A discontinuity in credit availability, asserted as the basis for quasi-experimental identification, is missing in the data. By the same token, in the treatment group, but not the control group, many borrowers above the official wealth limit for eligibility are coded as eligible, suggesting endogeneity in this 'intention to treat' variable. Finally, the estimator is bimodal on the PK data, producing a mode with a positive impact estimate and a mode with a negative estimate. One cause appears to a long right tail in household consumption, the dependent variable of primary interest, which itself violates a normality assumption. Dropping the 16 rightmost observations in this tail, $0.4 \%$ of the sample, causes the two modes to collapse into one near zero-that is, to erase the PK finding. Instrument weakness may also play a role, as the bimodality appears to arise from the subsample in which the instruments are least able to differentiate impacts by gender. This paper is part of a debate that is notable for its length, complexity, and intensity (Morduch, 1998; Pitt 1999, 2011; Roodman and Morduch, 2011; PK, 2012). In our view, this odyssey offers two lessons for the social sciences in general. The first is about the limitations of the traditional journal review process and the value of replication in going beyond it. PK was published in the prestigious Journal of Political Economy after a rigorous review process. Still, journal editors and referees are limited in their abilities to fully assess studies. The anonymity that protects referees also limits their ability to communicate with authors to gain clarification. Referees' limited time and attention means that they rarely look at data 
The Impact of Microcredit on the Poor in Bangladesh: Revisiting the Evidence

and computer code to probe statistics on their own. They may not have visited the places under study, or have read more than a small slice of the cited literature. Referees focus on coherence, completeness, relevance, and originality. Their work goes far, but it is not a substitute for re-analysis. ${ }^{3}$ The work of clarification, replication, refutation, and extension is necessarily left to others, but scholars seldom directly replicate the work of others, especially in development studies, where the abundance of opportunities to break new ground imposes high opportunity costs on replication. ${ }^{4}$

The second lesson is about the value of open data and code sharing. Morduch began his dialogue with Pitt and Khandker in 1998. The present phase began with exchanges in 2007. While underlying survey data was shared early on, only in 2011 did a file become publicly available that included all constructed variables needed to run the regression of primary interest (Pitt, 2011). Its release was provoked by the first edition of this analysis, which itself entailed significant effort. Meanwhile, the original computer code is reportedly lost. Transparency in data and code could have shaved a decade off the scrutinizing of these influential, policy-relevant results. Such transparency is still far from the norm in the social sciences.

The paper runs as follows. Section 1 describes the PK estimator and explores its assumptions. Section 2 replicates the 'headline' regression relating to household consumption. Section 3 demonstrates four concerns about the estimator and tests fixes where possible. Section 4 analyses regressions of non-consumption outcomes. Section 5 concludes. 


\section{The econometrics of PK}

\subsection{The estimation problem}

PK analyse data from surveys of 1,798 households in 87 randomly selected villages within a randomly selected 29 of Bangladesh's 391 upazillas. Surveyors visited the households in 1991-92 after each of the three main rice seasons: aman (December-January), boro (AprilMay), and aus (July-August). Only 29 households attrited by the third round. Ten of the 87 villages had male microcredit borrowing groups, 22 had female groups, and 40 had both. All groups were single-sex. Credit programs of three institutions were evaluated: the Grameen Bank; a large non-governmental group called BRAC; and the official Bangladesh Rural Development Board (BRDB). According to PK (p. 959), all three programs essentially set eligibility in terms of land ownership: only functionally landless households, defined as those owning half an acre or less, could borrow. ${ }^{5}$ For statistical precision, the surveyors oversampled households poor enough to be targeted for microcredit. Since sampling on the basis of eligibility can bias results, PK incorporate sampling weights constructed from village censuses.

PK study six outcomes. Two are household-level: per-capita consumption and female-owned non-land assets. Four are individual-level: male and female labour supply and school enrolment of girls and boys. For each outcome, the three-way split by credit supplier and the two-way split by sex lead to six parameters of interest, the impact coefficients on credit by lender and gender. A central feature of the estimation problem is that the credit variables are at once presumed endogenous and bounded from below. Meanwhile, all of the outcomes except log household consumption are themselves bounded or binary. PK therefore estimate the impact parameters using a LIML framework that models the limited nature of all the endogenous variables. Each fitted model contains equations for the 
The Impact of Microcredit on the Poor in Bangladesh: Revisiting the Evidence

outcome variable of interest as well as for female borrowing and male borrowing. The outcome is variously modelled as Tobit, probit, or linear and unbounded.

\subsection{The estimator}

To state the PK model, we first need to formally describe access to credit. Let $p_{f}$ and $p_{m}$ be dummies indicating whether credit groups composed of females or males are operating in the village of a given household or household member; they capture credit availability by gender. Let $e$ be a dummy for whether a household is deemed eligible for a microcredit program, regardless of whether any borrowing groups operate in its village. Then the credit choice variables, indicating whether members of each sex can borrow, are

$$
\begin{aligned}
& c_{f}=p_{f} e \\
& c_{m}=p_{m} e
\end{aligned}
$$

A central contention in $\mathrm{PK}$ is that $c_{f}$ and $c_{m}$ are exogenous and excludable. This allows the availability of microcredit to be thought of as 'intent to treat,' and to instrument for actual uptake, or 'treatment.' The contention that $c_{f}$ and $c_{m}$ are good instruments is based in part on the idea that $e$ depends on the discontinuous half-acre eligibility rule.

Since we focus on the outcome log per-capita household consumption, the basis of PK's influential finding that microcredit reduces poverty, we take the outcome variable $y_{o}$ to be continuous and unbounded. Let $y_{f}\left(y_{m}\right)$ be the logarithm of total microcredit borrowings of all females (males) in a household. ${ }^{6}$ Let $\mathbf{y}_{f m} \equiv\left(y_{f 1}, y_{f 2}, y_{f 3}, y_{m 1}, y_{m 2}, y_{m 3}\right)^{\prime}$ be the six credit variables disaggregated by lender and gender. And let $\mathbf{x}$ be a vector of controls that includes the eligibility dummy $e, \log$ landholdings, household characteristics, village and survey round dummies, and a constant. ${ }^{7}$ Let $C_{t}$ be the credit censoring threshold, the minimum observable log borrowing amount among borrowers. If there is no borrowing, the 
household gets $C_{v}$, the censoring value for log borrowing assigned by the researcher (necessary since $\log 0$ is undefined). Then the PK estimation model, fit with maximum likelihood (ML), can be written as:

$$
\begin{aligned}
& y_{o}=\mathbf{y}_{f m}^{\prime} \boldsymbol{\delta}+\mathbf{x}^{\prime} \boldsymbol{\beta}_{o}+\epsilon_{o} \\
& y_{f}^{*}=\mathbf{x}^{\prime} \boldsymbol{\beta}_{f}+\epsilon_{f} \text { if } c_{f}=1 \\
& y_{m}^{*}=\mathbf{x}^{\prime} \boldsymbol{\beta}_{m}+\epsilon_{m} \text { if } c_{m}=1 \\
& y_{f}= \begin{cases}y_{f}^{*} & \text { if } c_{f}=1 \text { and } y_{f}^{*} \geq C_{t} \\
C_{v} & \text { otherwise }\end{cases} \\
& y_{m}= \begin{cases}y_{m}^{*} & \text { if } c_{m}=1 \text { and } y_{m}^{*} \geq C_{t} \\
C_{v} & \text { otherwise }\end{cases} \\
& \boldsymbol{\epsilon} \equiv\left(\epsilon_{o}, \epsilon_{f}, \epsilon_{m}\right)^{\prime} \\
& \boldsymbol{\epsilon} \mid \mathbf{x} \sim \operatorname{iid} \mathcal{N}(\mathbf{0}, \mathbf{\Sigma})
\end{aligned}
$$

where $\boldsymbol{\Sigma}$ is a $3 \times 3$ positive-definite symmetric matrix.

The PK model is unusual in several respects. The three main equations include the same exogenous regressors, $\mathbf{x}$ : seemingly, no instruments are excluded. The exogeneity of $c_{f}$ and $c_{m}$ is the asserted basis for identification, yet those dummies do not seem to serve as instruments. The credit equations' samples are restricted, so the number of equations in the model varies by observation. The outcome equation contains six endogenous credit variables, $\mathbf{y}_{f m}$, but the model includes just two instrumenting equations. The instrumenting stage is modelled as censored, which forces the unusual distinction between the censoring threshold, relevant for the Tobit modelling in the credit equations, and the censoring value, relevant for the treatment of credit on the right side of the outcome equation. And while PK set out to exploit a discontinuity in access to credit, the sample is not concentrated as in conventional Regression Discontinuity Design around the half-acre mark, but spans from a de minimus 0.1 acres to 5 acres. $^{8}$ This wide bandwidth necessitates a parametric approach. 


\subsection{A closer look at assumptions}

A key to understanding some of these unusual characteristics is to note that the last line of

(1) elides a complexity. The $y_{f}$ and $y_{m}$ equations are not defined over the full sample, so $\epsilon_{f}$, $\epsilon_{m}$, and the joint distribution $\mathcal{N}(\mathbf{0}, \boldsymbol{\Sigma})$ are not either. So to state the distributional assumption precisely, we distinguish the four possible cases of credit availability by gender. We use combinations of $o, f$, and $m$ subscripts to denote subvectors of $\epsilon$ and submatrices of $\boldsymbol{\Sigma}$ corresponding to combinations of the equations for the outcome, female credit, and male credit. A precise statement of the distributional assumption (not spelled out in PK) is then:

$$
\begin{aligned}
& \epsilon_{o} \mid \mathbf{x} \sim \mathcal{N}\left(0, \Sigma_{o}\right) \text { when } c_{f}=0, c_{m}=0 \\
& \boldsymbol{\epsilon}_{o f} \mid \mathbf{x} \sim \mathcal{N}\left(\mathbf{0}, \Sigma_{o f}\right) \text { when } c_{f}=1, c_{m}=0 \\
& \boldsymbol{\epsilon}_{\text {om }} \mid \mathbf{x} \sim \mathcal{N}\left(\mathbf{0}, \boldsymbol{\Sigma}_{\text {om }}\right) \text { when } c_{f}=0, c_{m}=1 \\
& \boldsymbol{\epsilon}_{\text {ofm }} \mid \mathbf{x} \sim \mathcal{N}\left(\mathbf{0}, \boldsymbol{\Sigma}_{\text {ofm }}\right) \text { when } c_{f}=1, c_{m}=1
\end{aligned}
$$

where $\boldsymbol{\epsilon}_{o f m} \equiv \boldsymbol{\epsilon}$ and $\boldsymbol{\Sigma}_{o f m} \equiv \boldsymbol{\Sigma}$. Every case implies $\varepsilon_{o} \mid \mathbf{x} \sim \mathcal{N}\left(0, \Sigma_{o}\right)$. Thus

$$
\epsilon_{o} \mid \mathbf{x}, c_{f}, c_{m} \sim \mathcal{N}\left(0, \Sigma_{o}\right)
$$

That is, knowing credit availability by gender tells us nothing about the distribution of $\epsilon_{o}$. This is how the identification strategy implies and requires that credit choice is exogenous. One can gain further intuition by innocuously inserting $c_{f}$ and $c_{m}$ into the latent credit equations in (1):

$$
\begin{aligned}
& y_{f}^{*}=c_{f} \mathbf{x}^{\prime} \boldsymbol{\beta}_{f}+\epsilon_{f} \text { if } c_{f}=1 \\
& y_{m}^{*}=c_{m} \mathbf{x}^{\prime} \boldsymbol{\beta}_{m}+\epsilon_{m} \text { if } c_{m}=1
\end{aligned}
$$

This communicates the idea that $c_{f} \mathbf{x}$ and $c_{m} \mathbf{x}$ are the instruments, being excluded from the $y_{o}$ equation. And since $\mathbf{x}$ includes a constant, $c_{f}$ and $c_{m}$ are now seen as instruments too.

One important question about the PK estimation model is whether its distributional 
The Impact of Microcredit on the Poor in Bangladesh: Revisiting the Evidence

assumptions must hold strictly for the estimates of $\boldsymbol{\delta}$ to be consistent. ML estimation of misspecified models can be consistent for some parameters (White, 1982). For example, linear LIML is naturally derived from a model that assumes iid normal errors, but is consistent under substantial violations of that assumption: errors need not be normal, and they need only be uncorrelated with the instruments, not independent (Anderson and Rubin 1950). ${ }^{9}$

The nonlinearities in the PK estimator turn out to make it less robust to such violations. For example, the estimator is inconsistent if $\epsilon_{o}$ has skewness, as simulations in the appendix demonstrate. Similarly, if the first-stage Tobit models are not exactly correct, then the estimator should be presumed inconsistent (Angrist and Krueger 2001). In contrast, a linear instrumental variables (IV) estimator defined along the lines of (3)-instrumenting with $c_{f} \mathbf{X}$ and $c_{m} \boldsymbol{x}$ and dispensing with the Tobit modelling of borrowing - is consistent regardless of the true functional form and error distribution of the first stage (Kelejian, 1971).

The PK specifications that include village dummies in $\mathbf{x}$, among them the headline regression suggesting that microcredit reduces poverty, are akin to the difference-indifferences (DID) estimator with controls. The two dimensions of difference are the eligibility of a household for microcredit (indicated by $e$ ) and the availability of microcredit in a village $\left(p_{f}\right.$ and $\left.p_{m}\right)$. As in DID, identification comes from variation associated with the excluded products $p_{f} e$ and $p_{m} e$ conditional on the included factors $p_{f}, p_{m}$, and $e\left(p_{f}\right.$ and $p_{m}$ being controlled for through the village dummies). ${ }^{10}$ The validity of the exclusion assumption is open to question (Morduch, 1998). For example, in villages where eligible households are relatively well-off, credit group formation may be more likely. In this way, village effects may interact with eligibility to cause outcomes through channels separate 
The Impact of Microcredit on the Poor in Bangladesh: Revisiting the Evidence

from microcredit.

\section{Replication}

Pitt (2011) provides a data set adequate for replicating the PK regression of primary interest, with $y_{o}$ as log per-capita household consumption. The first and second moments of regression variables in the Pitt (2011) data closely match those reported in PK - though not exactly. ${ }^{11}$ (See Table 1 and Table 2.)

The five other PK outcomes are not in the Pitt (2011) data, nor in a set sent earlier to us by Mark Pitt. So we construct those outcomes from the underlying survey data. Among the five, the match is extremely good for male labour supply and boys' and girls' school enrolment. It is poorer for female labour supply. But here we have reason to doubt PK's aggregates. PK (2002, Table 1) reports the same means alongside mathematically incompatible seasonal subaverages. Finally, the biggest discrepancies are in female-owned non-land assets. As shown, we obtain a much better match if we include land in 'nonland' assets.

The first column of Table 3 shows PK's preferred fixed-effect estimates of the impact of microcredit on household consumption by gender and lender. The second shows our best replication, using the $\mathrm{cmp}$ program for Stata (Roodman, 2011). ${ }^{12}$ The matches for the female credit coefficients are excellent. Those for male credit are statistically similar. The estimated correlations of $\epsilon_{o}$ with $\epsilon_{f}$ and $\epsilon_{m}$, labelled ' $\rho$ female' and ' $\rho$ male,' also match well. ${ }^{13}$ The apparent small differences in the underlying data, as well as subtle differences among nonlinear estimation packages (McCullough and Vinod 2003), probably explain the imperfections in the match.

Near the bottom of Table 3 are reported the skew and kurtosis of the estimation 
The Impact of Microcredit on the Poor in Bangladesh: Revisiting the Evidence

residuals. In every case they differ from the values for the normal distribution (skew of 0 and kurtosis of 3 ) with significance levels below $10^{-10}$ according to the test of $D^{\prime}$ Agostino, Belanger, and D'Agostino Jr. (1990). ${ }^{14}$ We will return later to this violation of the PK model.

\section{Specification problems in PK}

Morduch (1998) identifies several concerns with the headline PK specification. Our analysis exposes more. This section inventories the problems and applies fixes where possible.

\subsection{The logarithm of zero}

Analysis using the logarithm of credit requires imputing some value for observations where credit is 0. Here, the choice is doubly tricky. As displayed in (1), the PK estimation model creates a distinction between the censoring threshold for credit, $C_{t}$, and censoring value, $C_{v}$. PK set $C_{t}=\log 1,000$ since 1,000 taka is the smallest observed amount of cumulative total borrowing. That is, the Tobit likelihoods for the first-stage equations is computed as if every non-borrowing household had to borrow at least 1,000 taka. But PK set $C_{v}=\log 1=0$. That is, in the second-stage equation non-borrowers are modelled as receiving 1 taka of treatment. Since household consumption is also taken in logs-so that coefficients on credit are elasticities - the latter assumption implies that, ceteris paribus, moving from nonborrowing status, proxied by 1 taka, to minimal borrowing status $-1,000$ taka, or about $\$ 25-$ has the same proportional impact as moving from 1,000 to $1,000,000$ taka of borrowing. (The highest observed cumulative borrowing is 58,800 taka.) That is a strong, unstated, and unexamined assumption.

It is also econometrically influential. PK could have set $C_{v}=\log 10$ or $\log 0.1$. The differences among these choices are pennies in levels, but substantial in logs. The lower the censoring value, the greater the variance in log credit, thus the smaller the expected best-fit 
The Impact of Microcredit on the Poor in Bangladesh: Revisiting the Evidence

slope coefficients in a regression of consumption on log credit. Figure 1 illustrates by showing the data with the censoring value at $\log 1$, which PK use, and alternatively at log 1,000 . One can see why the slope of a best-fit line would vary substantially as the censoring value changes. Since the impact estimates in PK are based on this arbitrary choice, their magnitude is unidentified. ${ }^{15}$

The deep problem is that the elasticity construct implied by regressing logs on logs does not allow for zero values. Thus a hypothetical move from non-borrowing to borrowing status lies outside the construct, and can only be linked to it through an auxiliary assumption about the impact of such a non-marginal move relative to a marginal increase in borrowing. A better solution to this conundrum would be to enter borrowing dummies and borrowing amounts separately in the $y_{o}$ equation. But we see no good instruments for borrowing amounts as distinct from borrowing decisions.

In fact, the key instruments in the PK model, $c_{f}$ and $c_{m}$, can be expected to be strong only for the borrowing decision. Thus to the extent that the PK estimator is succeeding in identifying impacts, these are mainly the average impacts of becoming a borrower. In this light, the PK conclusion about the marginal impacts of borrowing arises from a conversion of an average impact into a marginal one by way of an assumption that becoming a minimal borrower has the same proportional impact as increasing borrowings a thousandfold.

More practical than simultaneously modelling the borrowing decision and borrowing amount is to focus on the first: simply model borrowing as dichotomous. This circumvents the question of how to handle the log of 0 while focusing on the variation in borrowing for which credit choice is a potentially strong instrument. Ironically, PK's use of an implausibly low censoring value pushes their model in this more meaningful direction by causing the variation associated with the borrowing decision - the wide gap between log 1 and log 
The Impact of Microcredit on the Poor in Bangladesh: Revisiting the Evidence

1,000 in Figure $1-$ to dominate total variation in credit. So it is not surprising that 'probitizing' the credit model in this way corroborates PK's results. (See column 3 of Table

3.) Going by these new point estimates, households in which women took microcredit had about $e^{0.38}-1=46.2$ per cent higher per-capita consumption. However, PK's translation of this average effect into a marginal one-'household consumption expenditure increases 18 taka for every 100 additional taka borrowed by women...compared with 11 taka for men'-appears unfounded.

\subsection{A missing discontinuity}

PK buttress the claim that $c_{f}$ and $c_{m}$ are exogenous by pointing to two factors: the arbitrariness of the half-acre eligibility cut-off, and the exogeneity of landownership. On the latter, they write, 'Market turnover of land is well known to be low in South Asia. The absence of an active land market is the rationale given for the treatment of landownership as an exogenous regressor in almost all the empirical work on household behaviour in South Asia' (p. 970). However, this appears to be a case for landholdings being external to the model (Heckman, 2000). Exogeneity is a distinct notion (Brock and Durlauf, 2001; Deaton, 2010), requiring that the characteristic of owning more than half an acre relates to outcomes only through microcredit (after linearly conditioning on controls, including log landholdings).

Thus whether an eligibility dummy based on the half-acre rule is exogenous is a distinct question from whether land turnover was low in the study area. The question is also less relevant than first appears, for PK use no such dummy (Morduch, 1998). PK's eligibility dummy is defined strictly on the half-acre rule only for villages without microcredit. In program villages, 203 of the 905 borrowing households-a weighted 24 per cent of 
The Impact of Microcredit on the Poor in Bangladesh: Revisiting the Evidence

borrowing households-owned more than half an acre before borrowing. PK classify all as eligible. As a result, the dummy $e$ departs substantially from the de jure definition of eligibility.

So there are two caveats for the estimation here: the identifying variation in $e$ lacks discontinuity, and it is presumably endogenous. To illuminate the matter, we follow the advice of Imbens and Lemieux (2008) on preliminaries to discontinuity-based regression, by plotting the key regressors $y_{f}$ and $y_{m}$ against the continuous forcing variable, household landholdings before borrowing. See Figure 2. We perform Lowess regressions separately for the below- and above-threshold subsamples in order to allow a discontinuity at the halfacre mark. ${ }^{16} 95$-per-cent confidence intervals are shown. The plots are restricted to households for which $p_{f}=1$ (for female borrowings) or $p_{m}=1$ (male borrowings). Per PK, non-borrowers are assigned 1 taka of borrowing. Effective enforcement of the half-acre eligibility criterion would cause the borrowing curves to plunge near the threshold. Instead they hop a bit in opposite directions, without statistical significance. Evidently, loan officers were either unaware of the formal half-acre eligibility rule or pragmatically bending it to extend credit to borrowers who seemed reliable and who were, after all, poor by global standards. Some over-half-acre households that borrowed may have met an alternative eligibility criterion (see footnote 5), but this cannot explain such substantial mistargeting. At any rate, the asserted basis for quasi-experimental identification is invisible in the data.

Morduch (1998) makes most of these points. Pitt's (1999) argues that the true microcredit eligibility rule is 'unknown' (presumably being a function of land quality, not just quantity, and other factors tied to poverty) and that identification in PK's IV set-up requires only that the exogenous half-acre rule drive a component of variation in borrowing. In effect, Pitt casts the identification strategy as a Fuzzy Regression Discontinuity design. ${ }^{17}$ 
The Impact of Microcredit on the Poor in Bangladesh: Revisiting the Evidence

This argument has two weaknesses. First, it concedes that the claimed quasiexperiment, central to PK's bid for credibility, is only asserted, not observed. Second, even if the quasi-experiment did occur, the PK model does not exploit it. In light of the pervasive non-enforcement of the rule evident in Figure 2, the eligibility dummy $e$ as defined and used by PK, and thus the key instruments, $c_{f}=p_{f} e$ and $c_{m}=p_{m} e$, is not defined by this rule and should be presumed endogenous. To properly exploit the quasi-experiment, PK's de facto eligibility dummy $e$ should be replaced by a de jure one built strictly on the half-acre rule.

We check the PK regression for robustness to this change. How requires explanation. A naïve implementation would replace $e$ throughout the model with $\tilde{e} \equiv \mathbf{1}$ \{landholdings $\leq$ 0.5 acres $\}$ and redefine the credit choice dummies as $\tilde{c}_{f} \mathbf{x} \equiv \tilde{e} p_{f} \mathbf{x}$ and $\tilde{c}_{m} \mathbf{x} \equiv \tilde{e} p_{m} \mathbf{x} . \mathbf{A}$ problem with this approach is that the mistargeted households that borrowed would now be excluded from the first-stage equations since for them $\tilde{c}_{f}=\tilde{c}_{m}=\tilde{e}=0$ and $\tilde{c}_{f}$ and $\tilde{c}_{m}$ define the first-stage samples. To include them in the instrumenting equations while defining the samples for those equations in a way that is more plausibly exogenous, we expand their samples to all households in villages with credit programs of the given gender. This puts all households in program villages, regardless of eligibility however defined, in the 'treatment' group. As Pitt (1999) points out, erring on the side of modelling more households as having access to credit does not affect consistency. Within these expanded samples, credit can then be instrumented as in (3) with $\tilde{c}_{f} \mathbf{x} \equiv \tilde{e} p_{f} \mathbf{x}$ and $\tilde{c}_{m} \mathbf{x} \equiv \tilde{e} p_{m} \mathbf{x}$. Roughly speaking, this instruments all treatments, targeted and mistargeted, with intent to treat.

Column 4 of Table 3 reports the results of such an alteration. It strengthens the PK results for female microcredit. This does not mean the PK instruments are valid (the lack of a discontinuity poses a serious problem for the motivation behind PK's identification 
The Impact of Microcredit on the Poor in Bangladesh: Revisiting the Evidence

strategy). But it does suggest that one potential source of invalidity, endogeneity tied to violation of the eligibility rule, is not driving the PK results.

\subsection{Correlation between the instruments and error}

We next examine more directly whether the instruments are valid even after the de jure redefinition. We do this by adding them linearly to the second-stage equation. The PK estimates are still technically identified under this change because their model's first stage is nonlinear. The second half of Table 3 reports the results of such tests. The first column shows the effect of introducing just $c_{f}$ and $c_{m}$ into the second stage while using PK's de facto eligibility definition. The next column adds all of $c_{f} \mathbf{x}$ and $c_{m} \mathbf{x}$. The second pair of columns parallels the first, but using the de jure definition. In all cases, the newly included instruments have clear explanatory power. As shown near the bottom of the table, the $p$ values on the Wald $F$ tests for the joint significance of the included instruments are less than $0.05 .^{18}$

Yet the PK results persist. Since including the instruments linearly does not drive out the PK results, it appears that nonlinear relationships between credit and household spending are generating the identification in PK. These relationships could be based on exogenous variation, but the linear endogeneity of the instruments makes this seem less likely.

\subsection{Instability}

We discovered that the PK likelihood on the PK data has two local maxima. (First two columns of Table 4.) The local maximum with the higher log likelihood yields the positive results in PK. The second one, not reported in PK, puts mildly negative coefficients on female credit and reverses the sign on the estimated the correlation between $\epsilon_{o}$ and $\epsilon_{f}$ (' $\rho$ 
The Impact of Microcredit on the Poor in Bangladesh: Revisiting the Evidence

female'). Its lower log likelihood, $-6,548$ instead of $-6,541$, arguably favours the published mode. But how meaningful this comparison is is not clear since the likelihood model is incorrect. As noted in section 2, the error is not normally distributed.

To illustrate the situation, we graph the likelihood as a function of $(1-\lambda) \widehat{\boldsymbol{\beta}}_{-}+\lambda \widehat{\boldsymbol{\beta}}_{+}$, where $\widehat{\boldsymbol{\beta}}_{-}$and $\widehat{\boldsymbol{\beta}}_{+}$are the two modes and $\lambda$ ranges between -1 and +2 . While all 255 parameters vary in this cross-section of the likelihood, the coefficients that change most are on female microcredit. So we label the $\lambda$ axis with the coefficient on female borrowings from the Grameen Bank. (See Figure 3.) ${ }^{19}$

The bimodal likelihood appears to lead to a bimodal estimator. The mechanism is intuitive: small changes in the data can perturb the relative heights of the two peaks or raise the trough between them just enough to turn two peaks into one. To demonstrate, we bootstrap the estimator's distribution with 1,000 samples from the PK data, drawing with replacement. Since PK reweight observations within villages, we draw at the village level (Field and Welsh, 2007). For each sample, we maximize the likelihood twice, starting the searches at the estimates in columns 1 and 2 of Table 4 . When two modes are found, the higher is retained. Figure 4 shows the distribution of this estimator as a histogram and as an Epanechnikov kernel density plot. 36 per cent of the distribution is below zero. Going by this bootstrapped distribution, which is more reliable under the circumstances than the classical standard errors, we cannot reject the null of zero or negative impact of female borrowing at conventional significance levels. The previously unremarked instability helps explain why the specification discrepancies in the first edition of this paper flipped the coefficients on female microcredit.

The theory of Maximum Likelihood does not guarantee that a correct likelihood is asymptotically unimodal. However, it does assure that when there are multiple modes, an 
estimator that picks the highest one will converge to the true parameters. The estimator will still be asymptotically unimodal. The apparent bimodality of the PK estimator, as distinct from the likelihood, is therefore a first-order concern. What is causing it? Our investigations suggest two factors: the model-violating skew in the second-stage error; and instrument weakness, at least in a subsample, brought on by the splitting of the borrowing variables by gender. Reducing either problem alone eliminates the bimodality-and the PK finding of positive impact-which suggests that the two factors are interacting to produce the published results. Meanwhile, a linear IV estimator whose required assumptions are more compatible with the data produces impact estimates indistinguishable from zero.

One way to remove the bimodality in the likelihood is to drop the observations in the long right tail in household consumption, the ones most responsible for the model-violating skew in the error. To demonstrate, we estimate our replication regression 50 times, first for the full sample, then excluding the highest-consumption observation, then the highest two, etc., up to the highest 49, initiating the searches in the same way as for Figure 4 . Figure 5 plots the discovered modes along with conventionally computed 95 per cent confidence intervals, once more labelling with the female Grameen impact coefficient. The upperrightmost dot represents our replication of the full-sample headline PK specification. The lower-rightmost dot is the alternate mode documented in Table 4. Scanning from right to left, we see that the two modes collapse into one near zero after dropping the 16 highestconsumption observations, which are associated with 14 households and constitute 0.4 per cent of the sample on a weighted basis. ${ }^{20}$

Another change that eliminates the finding of positive impact involves revisiting the gender split in the model. Recall that PK's key instruments $c_{f}$ and $c_{m}$ are products of two factors: the eligibility status of households, $e$, and the presence in a village of credit groups 
The Impact of Microcredit on the Poor in Bangladesh: Revisiting the Evidence

of each gender, $p_{f}$ and $p_{m}$. PK defend the exogeneity of the first factor, but not the second. Nor seemingly, is the latter as crucial to their project: since the main goal is to estimate the overall impact of microcredit, it is not obviously necessary for PK to disaggregate the model by gender. If they did not, they could define a single program placement dummy $p$; a single credit availability dummy $c \equiv p e$; and a single instrumenting equation for household borrowings. Because the exogeneity of $p_{f}$ and $p_{m}$ is neither essential nor defended, we try dispensing with it, by aggregating credit across gender. (See Table 4, column 3.) As one might expect, the point estimates of impact lie approximately halfway between those the replication puts on male and female credit. But statistical significance is lost, and we no longer find a second mode.

The loss of significance may merely be a sign of an imperfect model: female and male credit may have different impacts and so are better disaggregated. But the next four specifications challenge this position. Here, we retain PK's split by gender and instead drop parts of the sample. Since the sections dropped are defined by $p_{f}$ and $p_{m}$, asserted exogenous, this step does not introduce bias under PK's assumptions. First we drop households in villages where men can borrow. The resulting comparison of female-only to no-credit villages generates another estimate of the impact of microcredit for women. The next regression does the same for men. The third excludes only villages where both women and men can borrow. All these variants destroy the PK results. ${ }^{21}$

In contrast, the last variant (in the last column) is restricted to the complement of the previous one, villages in which both women and men could borrow. The coefficients on female credit are almost the same as in PK. Yet it is here that the instrumentation is weakest since here, $p_{f}=p_{m}=1$ and $c_{f}=c_{m}=e$. So the gender-differentiated choice instruments cannot differentiate impacts by gender. The PK result is strongest where the instruments 
The Impact of Microcredit on the Poor in Bangladesh: Revisiting the Evidence

are weakest.

Other arguments also point to instrument weakness as a source of the instability. In 2SLS and linear LIML, weak instrumentation is known to exaggerate the tendency toward bimodality (Phillips, 2006). Simulations in PK (2012) show how the same can happen in the nonlinear PK estimator. ${ }^{22}$ For a final probe into this matter, we run linear LIML, which opens the door to established tests of weakness. Linear LIML also has the advantage of being robust to deviations from normality, so it provides an additional check on the PK results. In particular, we expand the credit equations to the full sample, model credit as linear, and instrument with $c_{f} \mathbf{X}$ and $c_{m} \mathbf{x} .{ }^{23}$ In our first run, with six instrumented credit variables, it is not even certain that the regression is identified; we can reject the null of underidentification only at $p=0.179$ (column 1 of Table 5). Combining credit variables across lenders reduces the burden on the instruments and lifts the regression past that test (column 2), but the Kleibergen-Paap (2006) F statistic of weakness, is 5.944. This is well below Staiger and Stock's (1997) rule-of-thumb minimum of 10 for 2SLS. On the other hand, the test here may be distorted by the high number of instruments. When we strip the instrument set down to $c_{f}$ and $c_{m}$ (column 3), the weak identification check greatly improves: across the full sample at least, identification is strong.

The linear regressions require for consistency that $c_{f} \mathbf{x}$ and $c_{m} \mathbf{x}$ be uncorrelated with the error, an assumption questioned in section 3.3. In order to reduce endogeneity, we replace the de facto eligibility definition with the de jure as before. The change produces essentially the same pattern of results, albeit with weaker instruments (columns 4 and 5 of Table 5). Given the apparently endogenous recoding of the de facto eligibility variables, it is unsurprising that they are stronger, if more suspect, instruments for borrowing. For completeness, we repeat the previous two regressions while modelling credit as binary, for 
The Impact of Microcredit on the Poor in Bangladesh: Revisiting the Evidence

reasons given in section 3.1 (last two columns of Table 5). The last of these regressions is our preferred specification, being the most conservative and robust in PK and the present paper.

We draw two observations from the linear regressions. One is that these robust estimators never produce impact coefficients distinguishable from 0: in our experience, obtaining the PK result requires an estimator whose assumptions are especially incompatible with the data. Second, however, is that de facto credit choice instruments that PK use actually do not appear weak in the most conservative gender-split regression (column 3 of Table 5). ${ }^{24}$ Our best synthesis of the evidence relating to instrument weakness is that the PK results are generated in part by instrument weakness in a subsample, as suggest by the last regression of Table 4. This notion has little meaning or relevance for linear estimators, but appears more relevant for nonlinear ones. What is not in doubt is that we can only produce the PK result with an estimator whose assumptions conflict with the data, and that reducing that conflict-dropping the 16 most extreme consumption outliers-eliminates the PK result even when using the PK estimator.

\section{Other outcomes}

We attempt to replicate PK's results for the five outcomes other than per-capita household consumption. (See Table 6.) None of the results match PK exactly, but all are similar in signs and significance. The worst match, as in Table 2, is for female non-land assets; although even here, the results are not statistically different. Adding land to nonland assets gave us reasonable matches in first and second moments in Table 2 , but it does not aid us in matching regression results. We check all regressions for a second mode in the same manner as before. We find one only for male labour supply. The two discovered modes 
The Impact of Microcredit on the Poor in Bangladesh: Revisiting the Evidence

clash on the sign of the impact of male microcredit borrowing.

Given our doubts about the instrumentation strategy, we think the most important thing to observe about the six PK LIML fixed-effects estimates is that they are of two sorts. Those for female non-land assets, female labour supply, and girls' and boys' school enrolment feature insignificant coefficients on credit, insignificant $\rho$ parameters, and no apparent bimodality. In contrast, the household consumption and male labour supply results feature strong impact coefficients, significant $\rho$ parameters, and bimodality that produces starkly contradictory impact coefficients for one sex. This is further evidence that bimodality is the proximate cause of the significant results in PK's household consumption regression. Notably, this instability arises with the two least-bounded outcomes, the ones with the most scope for deviation from normality. Log household consumption is an unbounded variable. Male labour supply is bounded from below but assumes its bounding value of 0 in only 8.6 per cent of cases on a weighted basis.

\section{Conclusion}

Pitt and Khandker (1998) reinforced some broad ideas about microcredit: that it reduces poverty, and that it does so especially when given to women. In our view, nothing in the present paper contradicts those ideas. We stress that absence of evidence-lack of identification-is not evidence of absence. But the present paper should reduce confidence in the poverty-reducing power of microcredit to the extent that it rested on PK. Our critical conclusions about PK, combined with the muted results of the randomized trials of microcredit, mean that 35 years into the microfinance movement, credible evidence in favour of the proposition that microcredit reduces poverty is scarce (Armendáriz and Morduch, 2010, chapter 9; Odell, 2010; Duvendack et al., 2011; Roodman, 2012a, chapter 6). 
The Impact of Microcredit on the Poor in Bangladesh: Revisiting the Evidence

Our work replicating Pitt and Khandker (1998) has left us with great admiration for its sophistication and creativity. But its econometric sophistication obscures problems:

- an imputation for the log of the treatment variable when it is zero that is undocumented, influential, and arbitrary at the margin, making the impact size essentially identified;

- the absence of a discontinuity that is asserted as central to the identification strategy;

- a reclassification of formally ineligible but borrowing households as eligible, which presumably introduces endogeneity into the asserted quasi-experiment;

- a linear relationship between the instruments and the error;

- disappearance of the results when villages where both genders could borrow are excluded;

- instability in the estimator;

- disappearance of the results after dropping 16 outliers, 0.4 per cent of the sample, that especially violate a modelling assumption.

Our analysis raises a broad question about the value of non-randomized studies. Our prior is that exclusive reliance on one type of study, such as randomized ones, is not optimal. But for non-randomized studies to contribute to the measurement of causation in social systems, the quality of the natural experiments must be high, and demonstrated. ${ }^{25}$

Our replication also raises questions about quality control in the production of economics. Although some of the econometric tools we bring to bear were not developed or were less practical in the late 1990s than now, many relevant specification checks were practical: for the presence of an asserted discontinuity, for the normality of the errors, for robustness to outlier removal, for robustness to aggregation by gender; and for robustness 
The Impact of Microcredit on the Poor in Bangladesh: Revisiting the Evidence

to switching to linear LIML. Of course, hindsight is $20 / 20$. So we point up this issue not to engage in retrospective perfectionism but to draw lessons for social science today. What was and is reasonable to expect is that authors, reviewers, and journal editors take steps to prevent methodological complexity from obscuring fundamental issues of identification. Assumptions should be checked to the extent they can be. Dependence on secondary assumptions, such as that required in PK for the identification of impacts by gender, should be tested. Where possible, complex estimators should be checked by simpler ones.

A more radical strategy for quality control is transparency: sharing data and code starting at the working paper stage. Freely circulating data and code facilitates the scrutiny needed for science to proceed. The stakes are particularly high for research that influences policy (McCullough and McKitrick 2009). The Journal of Political Economy, which published PK, now requires such disclosure, although its data archive is among the least accessible (McCullough, McGeary, and Harrison, 2008). Our own transparency allowed Pitt (2011) to find the errors in our initial attempts at replication, which in turn led us to the most serious problems documented here. ${ }^{26}$ Had JPE enforced open data and code sharing in 1998, the debate over this study might have been resolved long ago.

\section{Notes}

\footnotetext{
${ }^{1}$ Randomized studies have found that access to capital increases average profitability of male-run microenterprises, but challenged the central claim that it does so for female-run businesses (see McKenzie and Woodruff 2008 on male-run businesses in Mexico and de Mel, McKenzie, and Woodruff 2008 on male- and female-run businesses in Sri Lanka). Other randomized studies find no support for the claim that microcredit increases household consumption within a few years (Banerjee et al., 2013; Karlan and Zinman 2011; Crépon et
} 
al., 2011; Attanasio et al., 2011; Augsburg et al., 2012; Angelucci, Karlan, and Zinman, 2013).

${ }^{2}$ For example, Appelbaum (2008), Yunus (1999; 2007; 2008), Yunus and Abed (2004). The

5\% figure comes from Khandker (1998: 56), which extrapolates from PK.

${ }^{3}$ McCullough and Vinod (2003, p. 888) advocate for replication emphatically. In their view, "Replication is the cornerstone of science. Research that cannot be replicated is not science, and cannot be trusted either as part of the profession's accumulated body of knowledge or as a basis for policy. Authors may think they have written perfect code for their bug-free software package and correctly transcribed each data point, but readers cannot safely assume that these error-prone activities have been executed flawlessly until the authors' efforts have been independently verified. A researcher who does not openly allow independent verification of his results puts those results in the same class as the results of a researcher who does share his data and code but whose results cannot be replicated: the class of results that cannot be verified, i.e., the class of results that cannot be trusted." ${ }^{4} \mathrm{~A}$ compounding problem is journals' relative lack of interest in publishing replication and re-analysis, in favour of publishing new findings. For a sustained perspective on the problems posed for the advancement of social science, see McCullough and Vinod (2003), McCullough et al. (2008), and McCullough and McKitrick (2009).

${ }^{5}$ Among the three creditors, at least Grameen also officially applied an alternative eligibility criterion: ownership of assets worth less than one acre of medium-quality land (The Grameen Bank Ordinance, as amended through 2008, §2(h).) However, PK rely exclusively on the half-acre rule in their analysis.

${ }^{6}$ PK measure credit as the simple sum of borrowings since 1986. If a woman borrowed 1,000 Bangladeshi taka, repaid it over a year, then repeated with cycles of 2,000,3,000, 
4,000 , and 5,000 , that would count as 15,000 in borrowings.

${ }^{7}$ PK include specifications that control for a set of village characteristics instead of a full set of village dummies. But the fixed-effect specifications are preferred, so we focus exclusively on them. Morduch (1999) notes that the village-level fixed effects are designed to control for non-random program placement, but in this instance they will only do so under restrictive assumptions. Even with village-level fixed effects, bias can emerge when programs base their placement decisions on the characteristics of sub-village groups. For example, programs may favour villages where part of the village is prospering and another segment is, so far, excluded from the gains. The village-level fixed effects will only control for the average characteristics of the village sample.

${ }^{8}$ PK exclude 41 households owning more than 5 acres.

${ }^{9}$ Lack of correlation, recall, is lack of linear relationship. As an example, a variate symmetrically distributed around 0 is uncorrelated with its square but entirely related to it. ${ }^{10}$ The comparison to standard DID is not exact because $\mathbf{x}$ includes additional controls, and $c_{f} \mathbf{X}$ and $c_{m} \mathbf{x}$ contain additional instruments.

${ }^{11}$ In addition, the Pitt (2011) data set, like PK, has the disadvantage of treating current students as having zero years of schooling.

12 Pitt (2011) first replicated PK with cmp. Our replication differs only in using first-round data for all three survey rounds in the first-stage equations, which, according to Pitt (2011), is what PK did.

${ }^{13}$ The first edition of this paper failed to replicate. Pitt (2011) pointed out two key discrepancies in our specification. We needed to include $e$ as a control, and we needed to censor ' $\log 0$ ' credit observations with $\log 1,000$ rather than $\log 1$. The first of these choices 
is documented in PK, the second not. Roodman and Morduch (2011) provide details.

${ }^{14}$ In an earlier version of this paper, we neglected to incorporate sampling weights into these calculations (PK, 2012). We correct the error here, and it increases the apparent deviations from normality.

${ }^{15}$ In fact, setting $C_{v}=\log 1,000$ flips the sign of the impact of female borrowing. This helps explain why the first edition of this paper failed to match PK, and is a sign of the instability discussed in section 3.4 .

${ }^{16}$ Taking Stata's defaults, the bandwidth for the Lowess regressions is an (unweighted) $80 \%$ of the sample. The local weighting function is tricubic and incorporates PK's sample weights. ${ }^{17}$ PK footnote 16: 'The quasi-experimental identification strategy used here is an example of the regression discontinuity design.'

${ }^{18}$ The first edition of this paper tested instrument validity through overidentification tests on analogous 2 SLS regressions, and reached the same conclusion. The new approach is an improvement because it is rooted in PK's specification.

${ }^{19}$ The picture is nearly identical for all three lenders.

${ }^{20}$ Since the concern about normality pertains to the residuals in the regression, not the outcome variable, it is arguably more correct to perform this exercise with respect to the former. On the other hand, if the regression is wrong, then so are the residuals computed from it. At any rate, using the residuals produces a similar graph, in which the two modes collapse more slowly.

${ }^{21}$ No estimate for BRAC microcredit is available in the regression excluding villages where women could borrow because BRAC did not lend to men.

${ }^{22}$ In an effort to rebut the arguments made here, they try to show that bimodality in the 
likelihood is a normal feature of the PK estimator. However, their simulations produce bimodality only by deviating from the PK model and estimator in two major ways that weaken instruments. They simulate borrowings as averaging zero in the treatment group, so that average treatment is the same for borrowers and non-borrowers and credit choice is a perfectly weak instrument for treatment. And they control for credit choice rather than instrumenting with it. (The other components of $c_{f} \mathbf{x}$ and $c_{m} \mathbf{x}$ remain as instruments.) As a result, the simulations bolster rather than rebut the hypothesis of a link between instrument weakness and bimodality.

${ }^{23}$ After proposing this approach (PK, 1998, note 16) and relying on it (Pitt, 1999), PK (2012) challenge it. They argue that even when identification is valid and strong in the PK estimator, the instruments in the corresponding linear IV estimator are weak. However, simulations in our appendix and in Pitt (1999) demonstrate the efficacy of linear IV. And the PK (2012) theoretical argument confuses individual and collective weakness (Roodman, 2012b). If $z_{1}$ is a weak instrument for $x_{2}$ and $z_{2}$ is weak for $x_{1}, z_{1}$ and $z_{2}$ can still be collectively strong for $x_{1}$ and $x_{2}$.

${ }^{24}$ PK (2012) challenge these regressions as presented in the working paper version. But our discussion here notes, as before, that the first regression in Table 5 is underidentified, and we do not rely on it for inference. And we here add the exactly identified regressions, which eliminate PK's concern about instrument proliferation and the rank-deficient covariance matrix of the moments.

${ }^{25}$ For more, see, for example, the debate between Banerjee and Duflo (2009) and Deaton (2010).

${ }^{26}$ Data and code for this paper are at j.mp/gpXml1. 


\section{References}

Anderson, T.W. and Rubin, H. (1950) The asymptotic properties of estimates of the parameters of a single equation in a complete system of stochastic equations. Annals of Mathematical Statistics, 21(4), pp. 570-582.

Appelbaum, R. (2008) The man who is creating a world without poverty. Santa Barbara Independent. January 10.

Angelucci, M., Karlan, D. and Zinman, J. (2013) Win some lose some? Evidence from a randomized microcredit program placement experiment by Compartamos Banco.

Angrist, J. D. and Krueger, A.B. (2001) Instrumental variables and the search for identification: From supply and demand to natural experiments. Journal of Economic Perspectives, 15(4), pp. 69-85. Armendáriz de Aghion, B. and Morduch, J. (2010) The Economics of Microfinance. $2^{\text {nd }}$ ed. Cambridge, MA: The MIT Press.

Attanasio, O., Augsburg, B., De Haas, R., Fitzsimons, E. and Harmgart, H. (2011) Group lending or individual lending? Evidence from a randomised field experiment in Mongolia. Working Paper 11/20. Institute for Fiscal Studies.

Augsburg, B., De Haas, R., Harmgart, H. and Meghir, C. (2012) 'Microfinance at the margin:

Experimental evidence from Bosnia and Herzegovina.' European Bank for Reconstruction and Development.

Banjerjee, A.V. and Duflo, E. (2009) The experimental approach to development economics. Annual Review of Economics 1:151-178

Banerjee, A.V., Duflo, E., Glennerster, R. and Kinnan, C. (2013) The miracle of microfinance? Evidence from a randomised evaluation. Working Paper 18950. NBER. 
Baum, C., Schaffer, M.E. and Stillman, S. (2007) Enhanced routines for instrumental variables/GMM estimation and testing. Stata Journal, 7(4), pp. 465-506.

Brock, W.A. and Durlauf, S.N. (2001) Growth empirics and reality. World Bank Economic Review, 15(2), pp. 229-271.

Chemin, M. (2008) The benefits and costs of microfinance: Evidence from Bangladesh. Journal of Development Studies, 44(4), pp. 463-484.

Crépon, B., Devoto, F., Duflo, E. and Parienté, W. (2011) Impact of microcredit in rural areas of Morocco: Evidence from a randomized evaluation. Massachusetts Institute of Technology. D’Agostino, R. B., Belanger A. J. and D'Agostino Jr., R. B. (1990) A suggestion for using powerful and informative tests of normality. American Statistician, 44, pp. 316-321.

Deaton, A. (2010) Instruments, randomization, and learning about development. Journal of Economic Literature, 48(2), pp. 424-455.

Duvendack, M. and Palmer-Jones, R. (2012) High noon for microfinance impact evaluations: Reinvestigating the evidence from Bangladesh. Journal of Development Studies, 48(12), pp. 18641880.

Duvendack, M., Palmer-Jones, R., Copestake, J.G.. Hooper, L., Loke, Y. and Rao, N. (2011) What Is the Evidence of the Impact of Microfinance on the Well-Being of Poor People? EPPI-Centre, Social Science Research Unit, Institute of Education, University of London.

Field, C.A. and Welsh, A.H. (2007) Bootstrapping clustered data. Journal of the Royal Statistical Society B, 69(3), pp. 369-390.

Heckman, J.J. (2000) Causal parameters and policy analysis in economics: A twentieth century retrospective. Quarterly Journal of Economics, 115(1), pp. 45-97. 
The Impact of Microcredit on the Poor in Bangladesh: Revisiting the Evidence

Karlan, D. and Zinman, J. (2011) Microcredit in theory and practice: Using randomized credit scoring for impact evaluation. Science, 332(6035), pp. 1278-1284.

Kelejian, H.H. (1971) Two-stage least squares and econometric systems linear in parameters but nonlinear in the endogenous variables. Journal of the American Statistical Association, 66(334), pp. $373-374$.

Kleibergen, F. and Paap, R. (2006) Generalized reduced rank tests using the singular value decomposition. Journal of Econometrics, 127(1), pp. 97-126.

McCullough, B.D., McGeary, A. and Harrison, T.D. (2008) Do economics journal archives promote replicable research? Canadian Journal of Economics, 41(4), pp. 1406-1420.

McCullough, B.D. and McKitrick, R. (2009) Check the numbers: The case for due diligence in policy formation. Fraser Institute.

McCullough, B.D. and Vinod, H.D. (2003) Verifying the solution from a nonlinear solver: A case study. American Economic Review, 93(3), pp. 873-892.

De Mel, S., McKenzie, D. and Woodruff, C. (2008) Returns to capital in microenterprises: evidence from a field experiment. Quarterly Journal of Economics, 123(4), pp. 1329-1372.

McKenzie, D. and Woodruff, C. (2008) Experimental evidence on returns to capital and access to finance in Mexico. World Bank Economic Review 22 (3), pp. 457-482.

Morduch, J. (1998) Does microfinance really help the poor? New evidence from flagship programs in Bangladesh. New York University. j.mp/bC3Tge.

Morduch, J. (1999) The microfinance promise. Journal of Economic Literature, 37(4), pp. 1569-1614. Odell, K. (2010) Measuring the Impact of Microfinance: Taking Another Look. Grameen Foundation. Phillips, P.C.B. (2006) A remark on bimodality and weak instrumentation in structural equation 
estimation. Paper 1171. Cowles Foundation for Research in Economics. Yale University.

Pitt, M.M. (1999) Reply to Jonathan Morduch's 'Does microfinance really help the poor? New evidence from flagship programs in Bangladesh.' Brown University. j.mp/dLNItJ.

Pitt, M.M. (2011) Response to Roodman and Morduch's 'The impact of microcredit on the poor in Bangladesh: Revisiting the evidence.' Brown University. j.mp/j4x2xV.

Pitt, M.M. (2012) Gunfight at the not OK Corral: Reply to 'High noon for microfinance'. Journal of Development Studies, 48(12), pp. 1886-1891.

Pitt, M.M. and Khandker, S.R. (1998) The impact of group-based credit on poor households in Bangladesh: Does the gender of participants matter? Journal of Political Economy, 106(5), pp. 958996.

Pitt, M.M. and Khandker, S.R. (2002) Credit programs for the poor and seasonality in rural Bangladesh. Journal of Development Studies, 39(2), pp. 1-24.

Pitt, M.M. and Khandker, S.R. (2012) Replicating Replication: Due Diligence in Roodman and Morduch's Replication of Pitt and Khandker (1998). Working Paper 6273. World Bank.

Roodman, D. (2011) Estimating fully observed recursive mixed-process models with cmp. Stata Journal, 11(2), pp. 159-206.

Roodman, D. (2012a) Due Diligence: An Impertinent Inquiry into Microfinance. Washington, DC: Center for Global Development.

Roodman, D. (2012b) Perennial Pitt and Khandker. David Roodman's Microfinance Open Book Blog. 10 December. j.mp/11LrVRI.

Roodman, D. and Morduch, J. (2011) Comment on Pitt's Responses to Roodman and Morduch (2009). Center for Global Development. 
The Impact of Microcredit on the Poor in Bangladesh: Revisiting the Evidence

Staiger, D. and Stock, J.H. (1997) Instrumental variables regression with weak instruments. Econometrica, 65(3), pp. 557-586.

White, H. (1982) Maximum likelihood estimation of misspecified models. Econometrica, 50(1), pp. 125.

Yunus, M. (1999) The Grameen Bank. Scientific American. November.

Yunus, M. (2007) Q\&A with Muhammad Yunus. Interview on 'NOW.' PBS. j.mp/oEeNni.

Yunus, M. (2008) Credit for the poor. Harvard International Review. January.

Yunus, M. and Abed, F. (2004) Responses to New York Times editorial regarding new US law on poverty measurement tools. j.mp/o5xjq1. 
Table 1. Weighted means and standard deviations of individual- and household-level right-side variables, first survey round, as reported in PK and in reconstructions

\begin{tabular}{|c|c|c|c|c|}
\hline & \multicolumn{2}{|c|}{ Mean } & \multicolumn{2}{|c|}{ Standard deviation } \\
\hline & PK & New & PK & New \\
\hline Age of all individuals & 23 & 23 & 18 & 18 \\
\hline Schooling of individual 5 or above ${ }^{1}$ & 1.377 & 1.386 & 2.773 & 2.780 \\
\hline Parents of household head own land? & 0.256 & 0.250 & 0.564 & 0.559 \\
\hline \# of brothers of household head owning land & 0.815 & 0.796 & 1.308 & 1.298 \\
\hline \# of sisters of household head owning land & 0.755 & 0.737 & 1.208 & 1.197 \\
\hline Parents of household head's spouse own land? & 0.529 & 0.521 & 0.784 & 0.780 \\
\hline \# of brothers of household head's spouse owning land & 0.919 & 0.905 & 1.427 & 1.421 \\
\hline \# of sisters of household head's spouse owning land & 0.753 & 0.740 & 1.202 & 1.195 \\
\hline Household land (in decimals) & 76.142 & 75.883 & 108.54 & 107.98 \\
\hline Highest grade completed by household head' & 2.486 & 2.479 & 3.501 & 3.500 \\
\hline Sex of household head $(I=$ male $)$ & 0.948 & 0.947 & 0.223 & 0.223 \\
\hline Age of household head (years) & 40.821 & 40.803 & 12.795 & 12.790 \\
\hline Highest grade completed by any female household member' & 1.606 & 1.601 & 2.853 & 2.851 \\
\hline Highest grade completed by any male household member' & 3.082 & 3.069 & 3.081 & 3.7965 \\
\hline Adult female not present in household? & 0.017 & 0.017 & 0.129 & 0.130 \\
\hline Adult male not present in household? & 0.035 & 0.036 & 0.185 & 0.185 \\
\hline Spouse not present in household? & 0.126 & 0.126 & 0.332 & 0.332 \\
\hline Amount borrowed by female from BRAC (taka) & 350.345 & 350.369 & $1,573.65$ & $1,573.63$ \\
\hline Amount borrowed by male from BRAC (taka) & 171.993 & 171.973 & 1,565 & 1,565 \\
\hline Amount borrowed by female from BRDB (taka) & 114.348 & 114.119 & 747.301 & 746.722 \\
\hline Amount borrowed by male from BRDB (taka) & 203.25 & 202.793 & $1,572.66$ & $1,571.62$ \\
\hline Amount borrowed by female from Grameen (taka) & 956.159 & 953.581 & $4,293.36$ & $4,287.96$ \\
\hline Amount borrowed by male from Grameen Bank (taka) & 374.383 & 373.940 & $2,922.79$ & $2,921.46$ \\
\hline Nontarget household & 0.295 & 0.293 & 0.456 & 0.455 \\
\hline
\end{tabular}

$N=$ I,757. First two variables are reconstructed from PK survey data. Remainder are from Pitt (20I I).

'Treats current students as having no years of schooling. 
Table 2. Weighted means and standard deviations of endogenous variables as reported in PK and in reconstructions

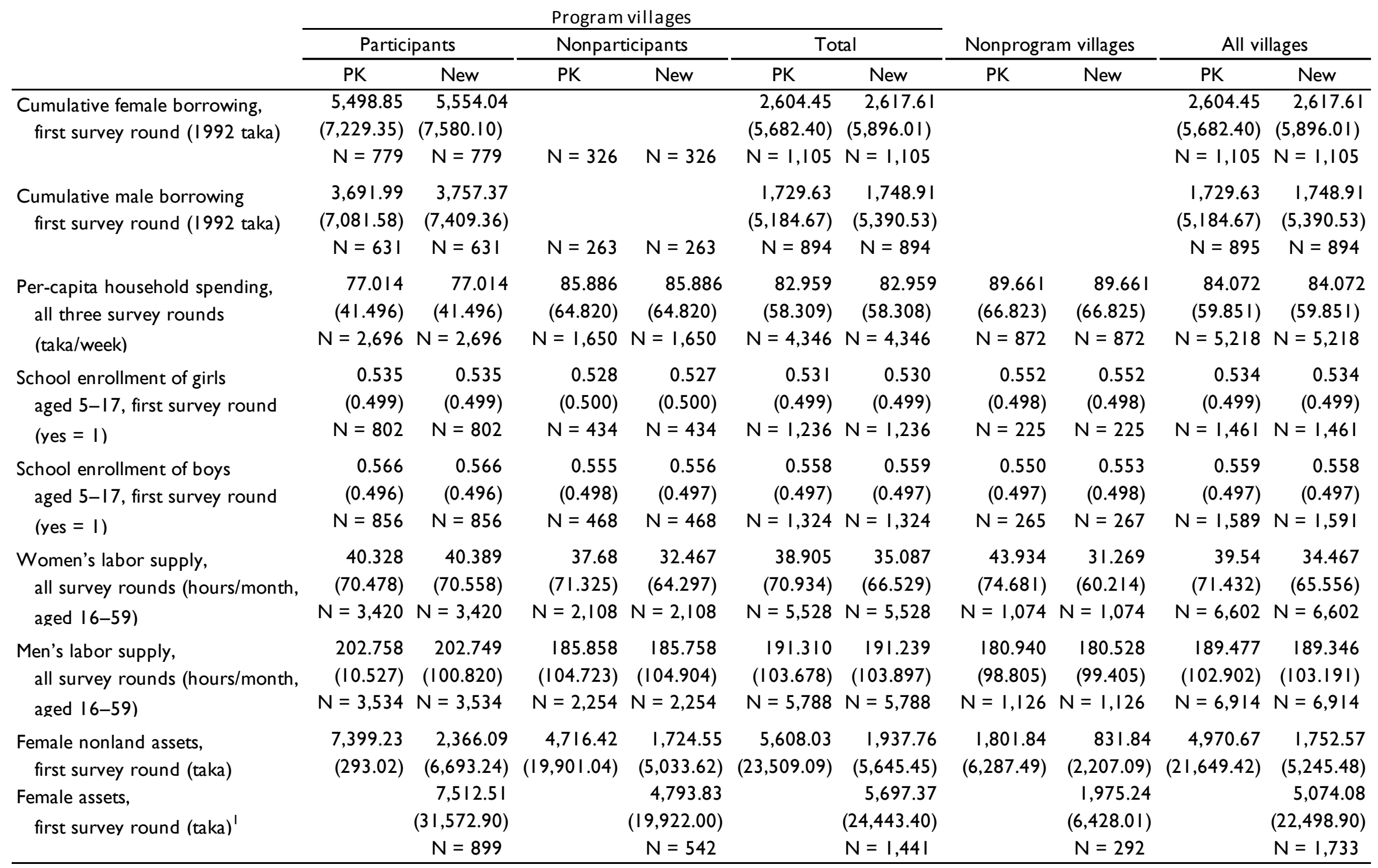

First three variables are from Pitt (20II). Remainder are reconstructed from PK survey data. 'Aggregates for this variable are displayed to show their similarity to PK's reported aggregates for non-land assets. 
The Impact of Microcredit on the Poor in Bangladesh: Revisiting the Evidence

Table 3. Replication and robustness tests of PK fixed-effects LIML household consumption regression

\begin{tabular}{|c|c|c|c|c|c|c|c|c|}
\hline \multirow[b]{3}{*}{ Explanatory variables } & \multirow[b]{3}{*}{ PK } & \multirow{2}{*}{\multicolumn{2}{|c|}{$1^{\text {st }}$ stage }} & \multirow[b]{3}{*}{ De jure } & \multicolumn{2}{|c|}{ De facto } & \multicolumn{2}{|c|}{ De jure } \\
\hline & & & & & \multirow[b]{2}{*}{ Add $c_{f}, c_{m}$} & \multicolumn{2}{|l|}{ Add } & \multirow{2}{*}{$\begin{array}{c}\text { Add } \\
c_{f} \mathbf{x}, c_{m} \mathbf{x}\end{array}$} \\
\hline & & Replication & probit & & & $c_{f} \mathbf{x}, c_{m} \mathbf{x}$ & Add $c_{f}, c_{m}$ & \\
\hline Log cumulative female & 0.0394 & 0.0389 & 0.3731 & 0.0428 & 0.0422 & 0.0346 & 0.0440 & 0.0398 \\
\hline borrowing, BRAC & $(4.237)^{\text {*10\% }}$ & $(3.987)^{\text {sele }}$ & $(4.649)^{\text {pere }}$ & $(7.510)^{\text {sete }}$ & $(5.019)^{\text {pete }}$ & $(3.914)^{\text {seck }}$ & $(8.052)^{\text {epek }}$ & $(7.352)^{\text {sem }}$ \\
\hline $\begin{array}{l}\text { Log cumulative female } \\
\text { borrowing, BRDB }\end{array}$ & $\begin{array}{c}0.0402 \\
(3.813)^{\text {tepes }}\end{array}$ & $\begin{array}{c}0.0407 \\
(3.643)^{\text {का }}\end{array}$ & $\begin{array}{c}0.3832 \\
(4.273)^{\text {sem }}\end{array}$ & $\begin{array}{c}0.0439 \\
(6.402)^{\text {teme }}\end{array}$ & $\begin{array}{c}0.0449 \\
(4.615)^{\text {tepto }}\end{array}$ & $\begin{array}{c}0.0401 \\
(3.888)^{* 0 \times k}\end{array}$ & $\begin{array}{c}0.0447 \\
(6.644)^{\text {)epec }}\end{array}$ & $\begin{array}{c}0.0393 \\
(5.805)^{\text {sete }}\end{array}$ \\
\hline $\begin{array}{l}\text { Log cumulative female } \\
\text { borrowing, Grameen }\end{array}$ & $\begin{array}{c}0.0432 \\
(4.249)^{\text {*em }}\end{array}$ & $\begin{array}{c}0.0425 \\
(4.032)^{\text {*em }}\end{array}$ & $\begin{array}{c}0.3874 \\
(4.844)^{\text {tem }}\end{array}$ & $\begin{array}{c}0.0446 \\
(7.842)^{\text {wete }}\end{array}$ & $\begin{array}{c}0.0459 \\
(5.045)^{\text {tete }}\end{array}$ & $\begin{array}{c}0.0404 \\
(4.329)^{* \infty<}\end{array}$ & $\begin{array}{c}0.0459 \\
(8.471)^{\text {)eck }}\end{array}$ & $\begin{array}{c}0.0386 \\
(7.409)^{\text {setek }}\end{array}$ \\
\hline $\begin{array}{l}\text { Log cumulative male } \\
\text { borrowing, BRAC }\end{array}$ & $\begin{array}{l}0.0192 \\
(1.593)\end{array}$ & $\begin{array}{l}0.0156 \\
(0.911)\end{array}$ & $\begin{array}{l}0.1316 \\
(0.721)\end{array}$ & $\begin{array}{l}0.0058 \\
(0.309)\end{array}$ & $\begin{array}{c}0.0272 \\
(2.272)^{* *}\end{array}$ & $\begin{array}{l}0.0101 \\
(0.669)\end{array}$ & $\begin{array}{l}0.0169 \\
(0.674)\end{array}$ & $\begin{array}{l}0.0073 \\
(0.448)\end{array}$ \\
\hline $\begin{array}{l}\text { Log cumulative male } \\
\text { borrowing, BRDB }\end{array}$ & $\begin{array}{l}0.0233 \\
(1.936)^{*}\end{array}$ & $\begin{array}{l}0.0182 \\
(1.024)\end{array}$ & $\begin{array}{l}0.1583 \\
(0.833)\end{array}$ & $\begin{array}{l}0.0095 \\
(0.489)\end{array}$ & $\begin{array}{c}0.0300 \\
(2.499)^{\text {*t* }}\end{array}$ & $\begin{array}{l}0.0139 \\
(0.957)\end{array}$ & $\begin{array}{l}0.0213 \\
(0.830)\end{array}$ & $\begin{array}{l}0.0116 \\
(0.726)\end{array}$ \\
\hline $\begin{array}{l}\text { Log cumulative male } \\
\text { borrowing, Grameen }\end{array}$ & $\begin{array}{l}0.0179 \\
(1.431)\end{array}$ & $\begin{array}{l}0.0132 \\
(0.755)\end{array}$ & $\begin{array}{l}0.1229 \\
(0.686)\end{array}$ & $\begin{array}{l}0.0041 \\
(0.210)\end{array}$ & $\begin{array}{c}0.0253 \\
(2.106)^{* *}\end{array}$ & $\begin{array}{l}0.0110 \\
(0.775)\end{array}$ & $\begin{array}{l}0.0160 \\
(0.620)\end{array}$ & $\begin{array}{l}0.0038 \\
(0.243)\end{array}$ \\
\hline$\rho$ female & $\begin{array}{l}-0.4809 \\
(4.657)^{+\infty 10 \%}\end{array}$ & $\begin{array}{l}-0.4739 \\
(4.340)^{\text {tepe }}\end{array}$ & $\begin{array}{l}-0.5533 \\
(5.414)^{\text {sete }}\end{array}$ & $\begin{array}{c}-0.5793 \\
(10.363)^{\text {+ete }}\end{array}$ & $\begin{array}{l}-0.4983 \\
(5.701)^{*+\infty}\end{array}$ & $\begin{array}{l}-0.4371 \\
(4.406)^{+\infty \text { eto }}\end{array}$ & $\begin{array}{l}-0.5929 \\
(12.051)^{\text {top }}\end{array}$ & $\begin{array}{c}-0.5417 \\
(10.202)^{\text {wete }}\end{array}$ \\
\hline$\rho$ male & $\begin{array}{c}-0.2060 \\
(1.432)\end{array}$ & $\begin{array}{c}-0.1314 \\
(0.607)\end{array}$ & $\begin{array}{c}-0.1593 \\
(0.561)\end{array}$ & $\begin{array}{l}-0.1156 \\
(0.469)\end{array}$ & $\begin{array}{l}-0.2643 \\
(1.998)^{* 0 \%}\end{array}$ & $\begin{array}{c}-0.0794 \\
(0.468)\end{array}$ & $\begin{array}{c}-0.2654 \\
(0.836)\end{array}$ & $\begin{array}{c}-0.1093 \\
(0.542)\end{array}$ \\
\hline \multicolumn{9}{|l|}{$2^{\text {nd }}$-stage errors } \\
\hline Skew & & $0.71^{* \infty \%}$ & $0.70^{\text {*em }}$ & $0.64^{* 0 \%}$ & $0.68^{* \infty \%}$ & $0.58^{\star \infty}$ & $0.61^{* \infty \%}$ & $0.54 \%$ \\
\hline Kurtosis & & $5.12^{* \%}$ & $5.07^{* 1 \%}$ & $5.04^{\text {wem }}$ & $4.94^{\text {wek }}$ & $4.68^{\text {mek }}$ & $4.94^{\text {*em }}$ & $4.80^{\text {wem }}$ \\
\hline $\begin{array}{l}\text { Instruments included linearly } \\
\text { ( } F \text { test } p \text { value })\end{array}$ & & & & & 0.041 & 0.000 & 0.000 & 0.000 \\
\hline Log likelihood & $-6,634$ & $-6,541$ & $-4,725$ & $-7,293$ & $-6,530$ & $-6,322$ & $-7,287$ & $-7,098$ \\
\hline Observations & 5,218 & 5,218 & 5,218 & 5,218 & 5,218 & 5,218 & 5,218 & 5,218 \\
\hline
\end{tabular}

Absolute $z$ statistics clustered by household in parenthesis. Statistical significance for kurtosis is relative to the null hypothesis that it is 3 , the kurtosis of the normal distribution. ${ }^{*}$ significant at $1 \%$. 
The Impact of Microcredit on the Poor in Bangladesh: Revisiting the Evidence

Table 4. Tests relating to bimodality and gender

\begin{tabular}{|c|c|c|c|c|c|c|c|}
\hline \multirow{3}{*}{$\begin{array}{c}\text { Explanatory variables } \\
\text { Log cumulative female } \\
\text { borrowing, BRAC }\end{array}$} & & & \multirow{3}{*}{$\begin{array}{c}\begin{array}{c}\text { Pool } \\
\text { accross }\end{array} \\
\text { gender' } \\
0.0239 \\
(1.039)\end{array}$} & \multicolumn{4}{|c|}{ Exclude villages with... } \\
\hline & \multicolumn{2}{|c|}{ Replication } & & \multirow{2}{*}{$\begin{array}{c}\begin{array}{c}\text { Male } \\
\text { groups }\end{array} \\
-0.0239 \\
(1.603)\end{array}$} & \multirow[t]{2}{*}{$\begin{array}{l}\text { Female } \\
\text { groups }\end{array}$} & \multirow{2}{*}{$\begin{array}{c}\begin{array}{c}\text { Both } \\
\text { kinds }\end{array} \\
-0.0168 \\
(0.314)\end{array}$} & \multirow{2}{*}{$\begin{array}{c}\begin{array}{c}\text { One or } \\
\text { no kinds }\end{array} \\
0.0383 \\
(2.003)^{* * *}\end{array}$} \\
\hline & $\begin{array}{c}0.0389 \\
(3.987)^{\text {*iek }}\end{array}$ & $\begin{array}{c}-0.0191 \\
(1.287)\end{array}$ & & & & & \\
\hline $\begin{array}{l}\text { Log cumulative female } \\
\text { borrowing, BRDB }\end{array}$ & $\begin{array}{c}0.0407 \\
(3.643)^{\text {teme }}\end{array}$ & $\begin{array}{c}-0.0219 \\
(1.334)\end{array}$ & $\begin{array}{l}0.0283 \\
(1.094)\end{array}$ & $\begin{array}{c}-0.0155 \\
(0.817)\end{array}$ & & $\begin{array}{c}-0.0073 \\
(0.119)\end{array}$ & $\begin{array}{l}0.0395 \\
(1.882)^{*}\end{array}$ \\
\hline $\begin{array}{l}\text { Log cumulative female } \\
\text { borrowing, Grameen }\end{array}$ & $\begin{array}{c}0.0425 \\
(4.032)^{\text {wete }}\end{array}$ & $\begin{array}{c}-0.0183 \\
(1.200)\end{array}$ & $\begin{array}{l}0.0255 \\
(1.033)\end{array}$ & $\begin{array}{c}-0.0154 \\
(1.102)\end{array}$ & & $\begin{array}{c}-0.0075 \\
(0.149)\end{array}$ & $\begin{array}{l}0.0418 \\
(1.875)^{*}\end{array}$ \\
\hline $\begin{array}{r}\text { Log cumulative male } \\
\text { borrowing, BRAC }\end{array}$ & $\begin{array}{l}0.0156 \\
(0.911)\end{array}$ & $\begin{array}{l}0.0221 \\
(1.460)\end{array}$ & & & & $\begin{array}{c}-0.0197 \\
(0.763)\end{array}$ & $\begin{array}{c}0.0431 \\
(3.782)^{+\infty+\infty}\end{array}$ \\
\hline $\begin{array}{l}\text { Log cumulative male } \\
\text { borrowing, BRDB }\end{array}$ & $\begin{array}{l}0.0182 \\
(1.024)\end{array}$ & $\begin{array}{l}0.0232 \\
(1.463)\end{array}$ & & & $\begin{array}{l}-0.0011 \\
(0.072)\end{array}$ & $\begin{array}{l}0.0010 \\
(0.067)\end{array}$ & $\begin{array}{c}0.0429 \\
(3.884)^{\text {ret }}\end{array}$ \\
\hline $\begin{array}{l}\text { Log cumulative male } \\
\text { borrowing, Grameen }\end{array}$ & $\begin{array}{l}0.0132 \\
(0.755)\end{array}$ & $\begin{array}{l}0.0214 \\
(1.385)\end{array}$ & & & $\begin{array}{c}-0.0097 \\
(0.455)\end{array}$ & $\begin{array}{l}-0.0020 \\
(0.121)\end{array}$ & 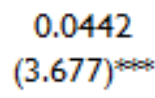 \\
\hline$\rho$ female & $\begin{array}{c}-0.4739 \\
(4.340)^{\text {tretex }}\end{array}$ & $\begin{array}{c}0.3160 \\
(1.7 \mid 6)^{*}\end{array}$ & & & & $\begin{array}{l}0.1779 \\
(0.245)\end{array}$ & $\begin{array}{l}-0.4170 \\
(1.872)^{*}\end{array}$ \\
\hline$\rho$ male & $\begin{array}{c}-0.1314 \\
(0.607)\end{array}$ & $\begin{array}{c}-0.2397 \\
(1.274)\end{array}$ & & & & $\begin{array}{l}0.0964 \\
(0.605)\end{array}$ & $\begin{array}{l}-0.4470 \\
(3.782)^{\text {sedet }}\end{array}$ \\
\hline \multicolumn{8}{|l|}{$2^{\text {nd }}$-stage errors } \\
\hline Skewness & $0.714^{\text {*o }}$ & $0.752^{\text {*eik }}$ & $0.776^{\text {*1\% }}$ & $0.483^{\text {*ek }}$ & $0.858^{\text {tekek }}$ & $0.693^{* \ldots *}$ & $0.742^{\text {* }}$ \\
\hline Kurtosis & $5.121^{\% 0 \%}$ & $5.370^{\text {tepes }}$ & $5.374^{\text {rep }}$ & $4.518^{\text {teek }}$ & $5.161^{\text {topk }}$ & $5.092^{\text {*eok }}$ & $5.028^{\text {teres }}$ \\
\hline Log likelihood & $-6,541$ & $-6,548$ & $-5,840$ & $-1,965$ & -971 & $-2,581$ & $-3,860$ \\
\hline Observations & 5,218 & 5,218 & 5,218 & 2,189 & $\mathrm{I}, 478$ & 2,795 & 2,423 \\
\hline
\end{tabular}

Absolute $z$ statistics clustered by village in parenthesis. 'Results in female credit rows are for toal borrowings by men and women. *significant at 10\%.* significant at $5 \%$ * * significant at $1 \%$. 
Table 5. Robustness and specification tests using linear LIML

De jure eligibility,

\begin{tabular}{|c|c|c|c|c|c|c|c|}
\hline \multirow[b]{2}{*}{ Instruments } & \multicolumn{3}{|c|}{ De facto eligibility } & \multicolumn{2}{|c|}{ De jure eligibility } & \multicolumn{2}{|c|}{ borrowing dichotomous } \\
\hline & $c_{f} \mathbf{x}, c_{m} \mathbf{X}$ & $c_{f} \mathbf{X}, c_{m} \mathbf{X}$ & $c_{f}, c_{m}$ & $c_{f} \mathbf{x}, c_{m} \mathbf{x}$ & $c_{f}, c_{m}$ & $c_{f} \mathbf{x}, c_{m} \mathbf{x}$ & $c_{f}, c_{m}$ \\
\hline Log cumulative female borrowing, & -3.816 & & & & & & \\
\hline BRAC & $(0.0 \mid 2)$ & & & & & & \\
\hline Log cumulative female borrowing, & -0.665 & & & & & & \\
\hline BRDB & $(0.013)$ & & & & & & \\
\hline Log cumulative female borrowing, & -0.783 & & & & & & \\
\hline Grameen & $(0.012)$ & & & & & & \\
\hline Log cumulative male borrowing, & 3.930 & & & & & & \\
\hline BRAC & $(0.0 \mid 3)$ & & & & & & \\
\hline Log cumulative male borrowing, & -2.229 & & & & & & \\
\hline BRDB & $(0.0 \mid 2)$ & & & & & & \\
\hline Log cumulative male borrowing, & $-0.8 \mid 4$ & & & & & & \\
\hline Grameen & $(0.0 \mid 3)$ & & & & & & \\
\hline Log cumulative female borrowing, & & 0.445 & 0.013 & 0.202 & 0.014 & 1.737 & 0.133 \\
\hline all lenders & & $(0.101)$ & $(0.697)$ & $(0.943)$ & $(0.353)$ & $(0.864)$ & $(0.38 \mathrm{I})$ \\
\hline Log cumulative male borrowing, & & 0.002 & -0.027 & -0.095 & -0.103 & -0.785 & -0.914 \\
\hline all lenders & & $(0.004)$ & $(1.159)$ & $(1.199)$ & $(\mathrm{l} .558)$ & $(1.080)$ & $(1.567)$ \\
\hline \multicolumn{8}{|l|}{$\begin{array}{l}\text { Log cumulative borrowing, } \\
\text { all lenders }\end{array}$} \\
\hline \multicolumn{8}{|l|}{ Kleibergen-Paap underidentification test } \\
\hline $\mathrm{H}_{0}$ : system is underidentified ( $p$ value) & 0.179 & 0.000 & 0.000 & 0.009 & 0.001 & 0.008 & 0.000 \\
\hline \multicolumn{8}{|l|}{ Kleibergen-Paap weak identification test } \\
\hline$F$ statistic & 1.67 & 5.94 & 60.17 & 2.24 & 5.92 & 2.27 & 6.14 \\
\hline Observations & 5,218 & 5,218 & 5,218 & 5,218 & 5,218 & 5,218 & 5,218 \\
\hline
\end{tabular}

Absolute $t$ statistics clustered by household in parenthesis. Coeffcients in last two columns are for borrowing dummies rather than log cumulative borrowings. 
Table 6. LIML fixed-effects estimates of impact of microcredit on outcomes other than consumption, PK and new

\begin{tabular}{|c|c|c|c|c|c|c|c|c|c|c|c|c|}
\hline \multirow[b]{3}{*}{ Log cumulative female } & \multicolumn{2}{|c|}{$\begin{array}{l}\text { Log female non-land } \\
\text { assets }\end{array}$} & \multirow{3}{*}{$\begin{array}{c}\text { Log female } \\
\text { assets }\end{array}$} & \multicolumn{2}{|c|}{$\begin{array}{l}\text { Log female labor } \\
\text { hours/month }\end{array}$} & \multicolumn{3}{|c|}{ Log male labor hours/month } & \multicolumn{2}{|c|}{$\begin{array}{c}\text { School enrollment of } \\
\text { girls, 5-17 }\end{array}$} & \multicolumn{2}{|c|}{$\begin{array}{c}\text { School enrollment of } \\
\text { boys, } 5-17\end{array}$} \\
\hline & \multirow{2}{*}{\begin{tabular}{|c|} 
PK \\
0.0318
\end{tabular}} & \multirow{2}{*}{$\begin{array}{c}\text { New } \\
0.1058\end{array}$} & & \multirow{2}{*}{$\begin{array}{c}\text { PK } \\
-0.0117\end{array}$} & \multirow{2}{*}{$\begin{array}{c}\text { New } \\
-0.0017\end{array}$} & \multirow{2}{*}{$\begin{array}{c}\text { PK } \\
-0.1813\end{array}$} & \multicolumn{2}{|c|}{ New } & \multirow{2}{*}{$\begin{array}{c}\text { PK } \\
-0.0203\end{array}$} & \multirow{2}{*}{$\begin{array}{c}\text { New } \\
-0.0567\end{array}$} & \multirow{2}{*}{$\begin{array}{c}\text { PK } \\
0.0394\end{array}$} & \multirow{2}{*}{$\frac{\mathrm{New}}{-0.005}$} \\
\hline & & & & & & & -0.2165 & -0.2277 & & & & \\
\hline borrowing, BRAC & $(0.356)$ & (1.488) & $(0.965)$ & $(0.128)$ & $(0.017)$ & $(5.884)^{\text {tepes }}$ & $(8.254)^{\text {tele }}$ & $(9.409)^{+\infty e-k}$ & $(0.552)$ & $(1.200)$ & $(0.917)$ & $(0.085)$ \\
\hline Log cumulative female & 0.1257 & 0.1565 & 0.0988 & -0.0139 & -0.0260 & -0.2308 & -0.2654 & -0.2723 & -0.0099 & -0.0541 & 0.1210 & 0.074 \\
\hline borrowing, BRDB & $(1.043)$ & $(1.717)^{*}$ & $(1.145)$ & $(0.139)$ & $(0.228)$ & $(7.066)^{\text {sepe }}$ & $(9.290)^{\text {tepe }}$ & $(10.499)^{\text {+ope }}$ & $(0.220)$ & $(0.988)$ & $(2.573)^{* *}$ & $(1.149)$ \\
\hline Log cumulative female & $|13|$ & 0.16 & 0.1435 & 0.0152 & 0.0 & -0.2189 & -0.2124 & -0.2183 & 0.0128 & -0.0301 & 1025 & 0.063 \\
\hline borrowing, Grameen & $(1.317)$ & $(2.349)^{* * *}$ & $(1.665)^{*}$ & $(0.162)$ & $(0.274)$ & $(6.734)^{\text {seck }}$ & $(9.127)^{\text {setok }}$ & $(10.104)^{\text {tepk }}$ & $(0.334)$ & $(0.721)$ & $(2.364)^{* 6 k}$ & $(1.319)$ \\
\hline Log cumulative male & 0.1005 & 0.0137 & -0.0210 & -0.0448 & -0.1052 & -0.1369 & -0.1634 & 0.0186 & 0.0495 & 0.0019 & -0.0040 & -0.000 \\
\hline borrowing, BRAC & $(0.468)$ & $(0.130)$ & $(0.243)$ & $(0.520)$ & $(1.085)$ & $(2.155)^{* k}$ & $(3.918)^{\text {sem }}$ & $(0.509)$ & $(1.152)$ & $(0.027)$ & $(0.107)$ & $(0.008)$ \\
\hline Log cumulative male & 0.0334 & -0.0940 & -0.1476 & -0.0144 & -0.0857 & -0.1440 & -0.1713 & 0.0154 & 0.0321 & -0.0162 & 0.0361 & 0.052 \\
\hline borrowing, BRDB & $(0.141)$ & $(0.879)$ & $(1.7 \mid 2)^{*}$ & $(0.18 I)$ & $(0.916)$ & $(2.129)^{* 0 *}$ & $(4.018)^{\text {tepes }}$ & $(0.409)$ & $(0.665)$ & $(0.240)$ & $(0.934)$ & $(0.957)$ \\
\hline Log cumulative male & -0.0457 & -0.1039 & -0.1798 & -0.0570 & -0.1044 & -0.1592 & -0.1584 & -0.0076 & 0.0582 & -0.0004 & 0.0736 & 0.095 \\
\hline borrowing, Grameen & $(0.200)$ & $(0.952)$ & $(2.086)^{* * *}$ & $(0.677)$ & $(1.24 I)$ & $(2.524)^{* * *}$ & $(4.354)^{\text {topek }}$ & $(0.229)$ & $(1.298)$ & $(0.007)$ & $(1.688)^{*}$ & $(2.025)^{* * *}$ \\
\hline \multirow[t]{2}{*}{$\rho$ female } & 0.1136 & 0.0718 & 0.0914 & 0.1255 & 0.1192 & 0.6564 & 0.6942 & 0.7358 & 0.1648 & 0.3042 & 0.2192 & 0.0184 \\
\hline & $(1.325)$ & $(0.657)$ & $(0.757)$ & $(1.062)$ & $(0.975)$ & $(7.461)^{\text {tepes }}$ & $(10.615)^{+\infty 10}$ & $(14.315)^{\text {+ete }}$ & $(1.029)$ & $(1.573)$ & $(1.054)$ & $(0.075)$ \\
\hline \multirow[t]{2}{*}{$\rho$ male } & -0.0148 & 0.1527 & 0.2256 & 0.0560 & 0.1298 & 0.4929 & 0.5091 & -0.0265 & -0.1360 & 0.0922 & -0.0284 & -0.1648 \\
\hline & $(0.053)$ & $(0.88 \mathrm{I})$ & $(1.126)$ & $(0.592)$ & $(1.228)$ & $(2.5 \mid 2)^{* *}$ & $(4.070)^{\text {sem }}$ & $(0.258)$ & $(0.720)$ & $(0.304)$ & $(0.177)$ & $(0.762)$ \\
\hline Observations & $\mathrm{I}, 757$ & ।,757 & $\mathrm{I}, 757$ & 6,602 & 6,602 & 6,914 & 6,914 & 6,914 & 2,885 & $\mathrm{I}, 443$ & 2,940 & I,587 \\
\hline Log pseudolikelihood & & $-4,048$ & $-4,195$ & & $-17,552$ & & $-20,865$ & $-20,875$ & & $-2,446$ & & $-2,737$ \\
\hline
\end{tabular}

Regressions for first two columns run on household-level data and the rest on individual-level.Absolute $z$ statistics clustered by household in parenthesis. *significant at

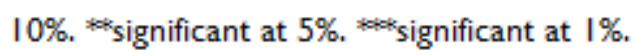


The Impact of Microcredit on the Poor in Bangladesh: Revisiting the Evidence

Figure 1. Household borrowing by women vs. household consumption, with censoring levels of log 1 or $\log 1,000$

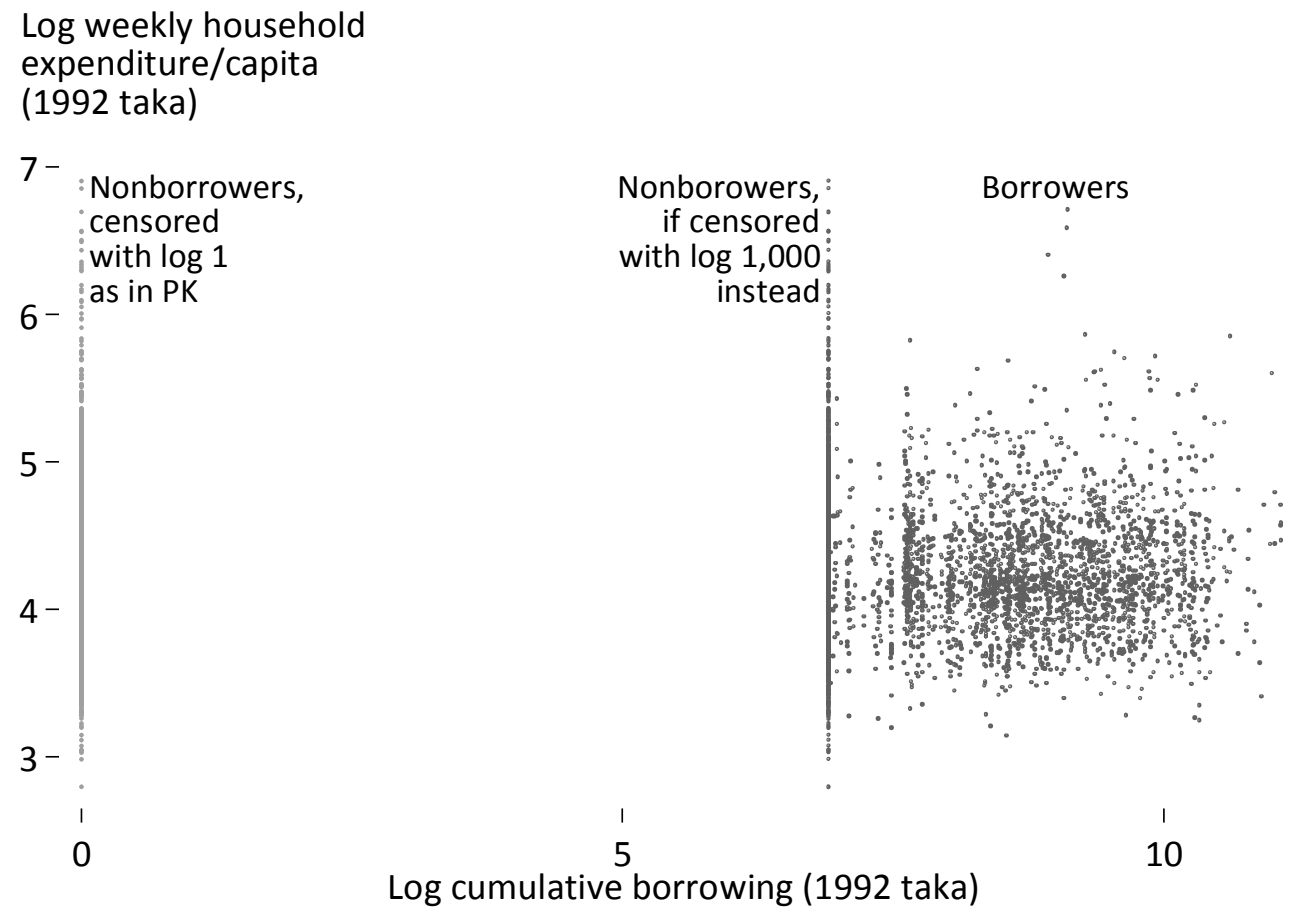


Figure 2. Cumulative borrowing vs. household landholdings before borrowing, first survey round, in villages with access to credit for given gender

Cumulative borrowing (1992 taka)
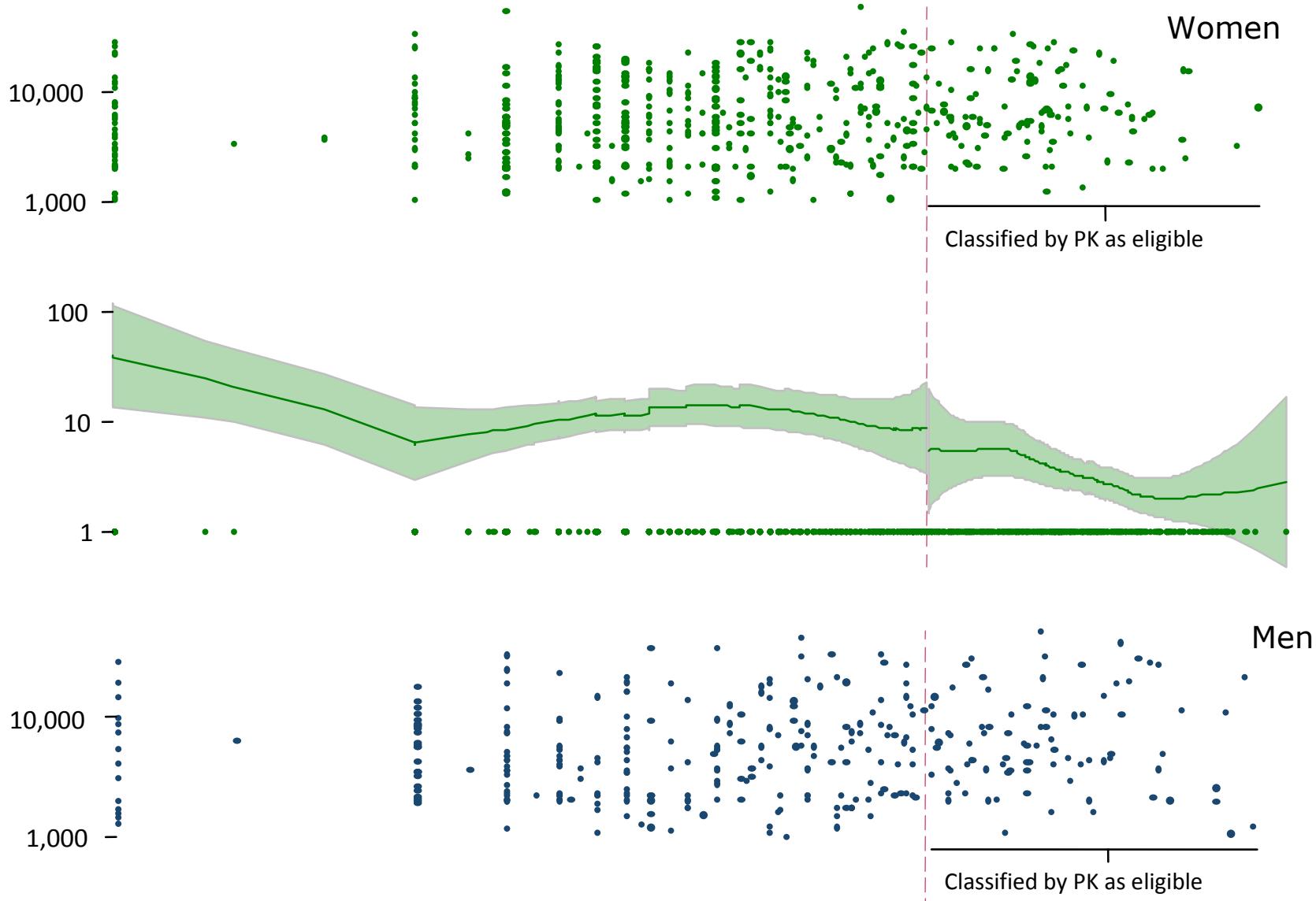

$100-$

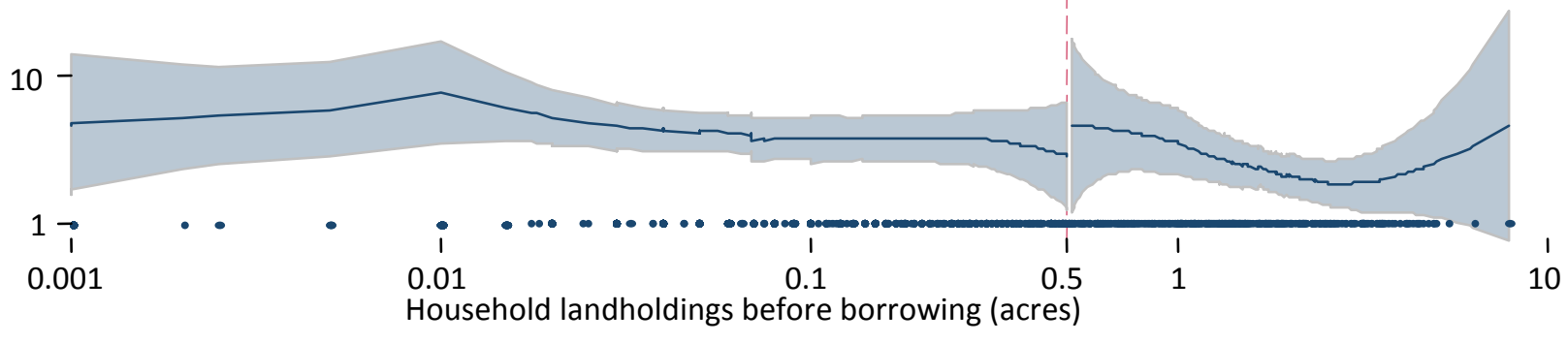


The Impact of Microcredit on the Poor in Bangladesh: Revisiting the Evidence

Figure 3. A cross-section of the PK likelihood on PK data, with two local maxima marked

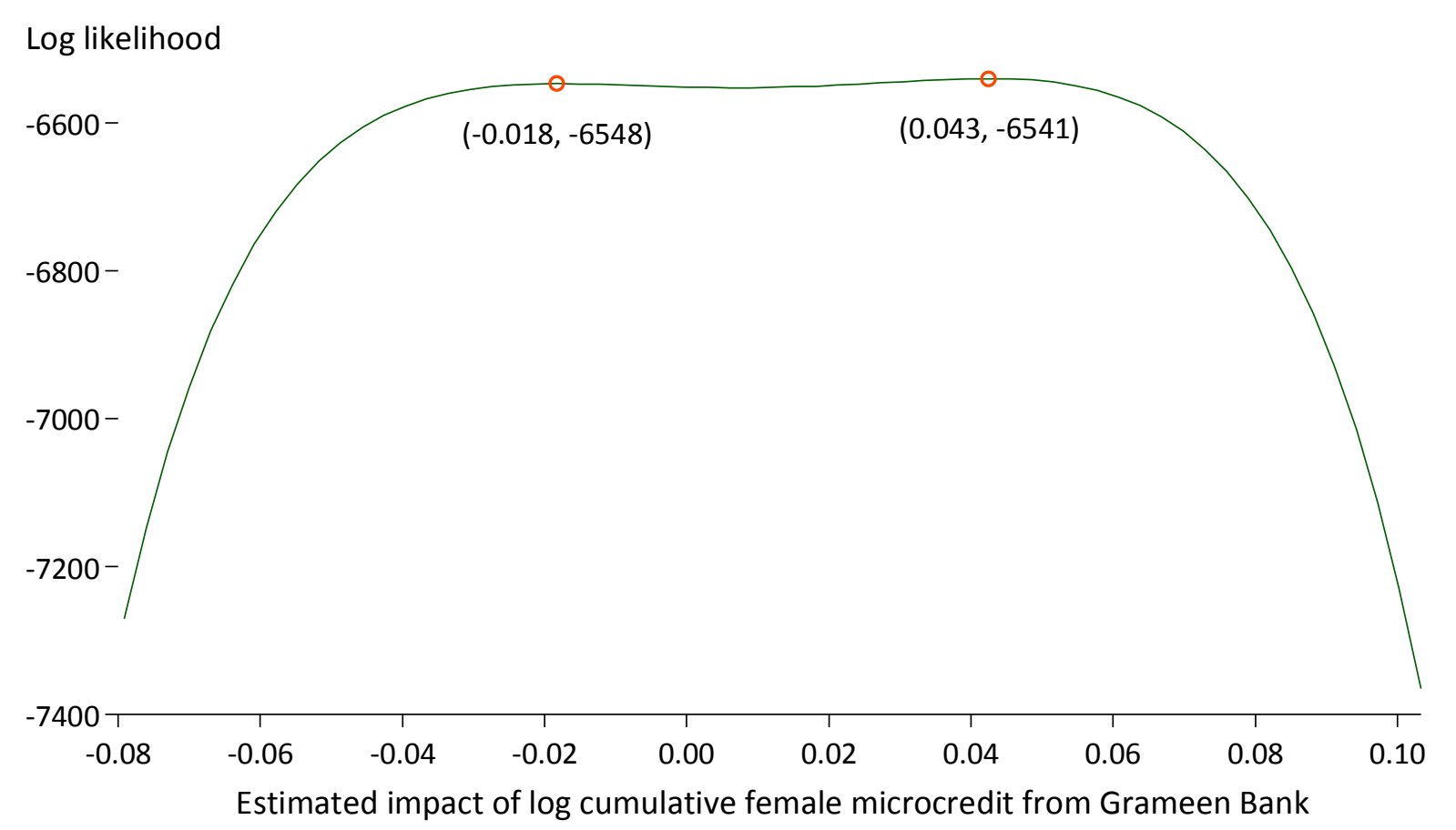


The Impact of Microcredit on the Poor in Bangladesh: Revisiting the Evidence

Figure 4. Bootstrapped distribution of the PK estimator on PK data, 1,000 replications

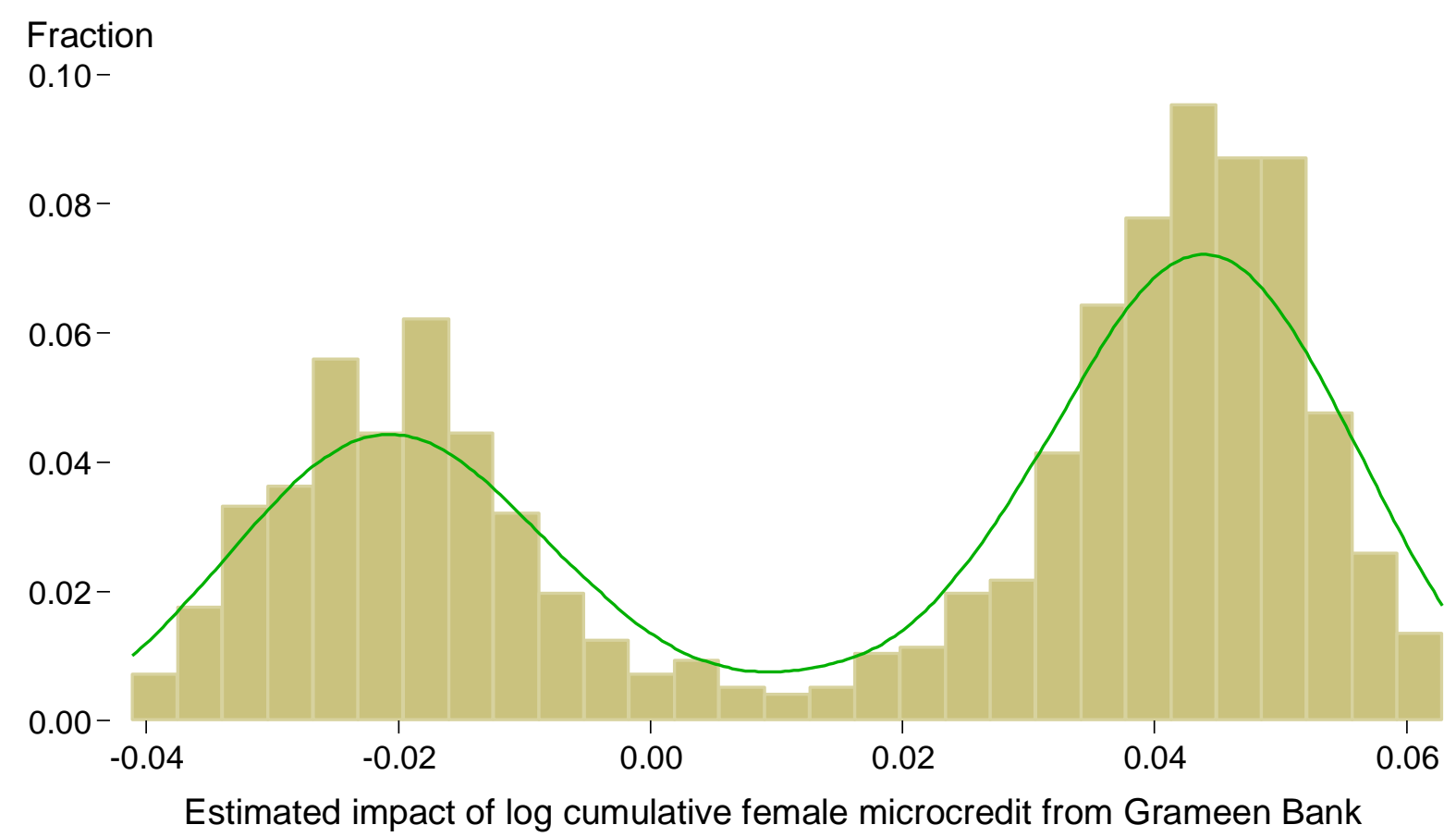


The Impact of Microcredit on the Poor in Bangladesh: Revisiting the Evidence

Figure 5. Modes of PK estimator on Pitt (2011) data when highest-consumption observations are excluded from sample, with conventional 95 per cent confidence intervals

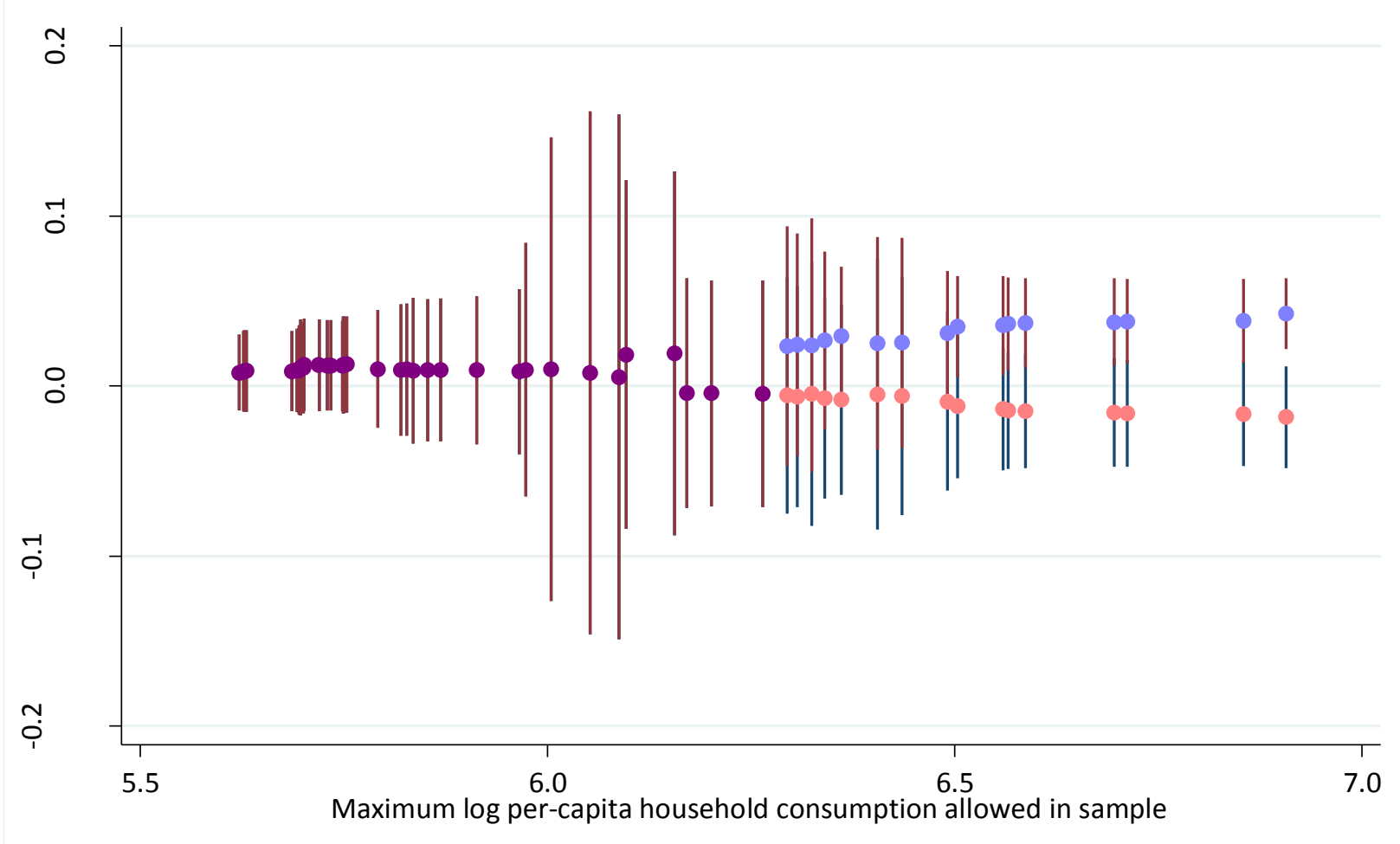




\section{Appendix 1. Linear LIML is robust to skew in errors and PK estimator is not}

We simulate two data-generating processes. The first complies with (1). Credit choice, $c_{f}$ and $c_{m}$, is random and uncorrelated across genders. Borrowing propensity, $y_{f}^{*}$ and $y_{m}^{*}$, is 0 where credit is unavailable, and is censored from below at 0 where credit is available. All errors are standard normal:

$$
\begin{aligned}
& \epsilon_{f}, \epsilon_{m}, \eta, c_{f}^{*}, c_{m}^{*} \sim \operatorname{iid} \mathcal{N}(0,1) \\
& \epsilon_{o}=\left(\epsilon_{f}+\epsilon_{m}+\eta\right) / \sqrt{3} \\
& c_{f}=\mathbf{1}\left\{c_{f}^{*}>0\right\} \\
& c_{m}=\mathbf{1}\left\{c_{m}^{*}>0\right\} \\
& y_{f}^{*}=c_{f} \epsilon_{f} \\
& y_{m}^{*}=c_{m} \epsilon_{m} \\
& y_{f}=\mathbf{1}\left\{y_{f}^{*}>0\right\} \cdot y_{f}^{*} \\
& y_{m}=\mathbf{1}\left\{y_{m}^{*}>0\right\} \cdot y_{m}^{*} \\
& y_{o}=1 \cdot y_{f}+1 \cdot y_{m}+\epsilon_{o}
\end{aligned}
$$

The parameters of interest are the coefficients in the last line.

The second data-generating process differs only in transforming $\epsilon_{o}$ after the second line above to have a $\chi^{2}(15)$ distribution that is shifted and scaled to keep the mean and variance at 0 and 1. The transformation is $\left(\Xi_{15}^{-1}(\Phi(\cdot))-15\right) / \sqrt{2 \times 15}$, where $\Xi_{15}^{-1}(\cdot)$ is the inverse c.d.f. of the $\chi^{2}(15)$ distribution and $\Phi(\cdot)$ is the standard normal c.d.f. This gives $\epsilon_{o}$ a skew of $\sqrt{8 / 15} \approx 0.73$, close to the value found reported in Table 3 for the PK replication.

We apply linear LIML and PK's estimator to 100 simulated data sets of each variety. The 
The Impact of Microcredit on the Poor in Bangladesh: Revisiting the Evidence

linear LIML regressions instrument $y_{f}$ and $y_{m}$ with $c_{f}$ and $c_{m}$. The results confirm that, contrary to the criticism in PK (2012) relating to weak instruments, linear LIML is consistent; and that the PK estimator is more efficient when its assumptions are satisfied (left half of Table A-1). But when the normality assumption is violated (right half), the PK estimator is inconsistent. This again contradicts PK (2012) - or at least answers their argument that no one has proved that their estimator is inconsistent.

Table A-1. Mean coefficient estimates, 100 simulations, with and without skew in secondstage error

\begin{tabular}{lrrrrr} 
& \multicolumn{2}{c}{ Normal error } & & \multicolumn{2}{c}{ Skewed error } \\
\cline { 2 - 3 } \cline { 5 - 6 } & \multicolumn{1}{c}{$y_{f}$} & \multicolumn{1}{c}{$y_{m}$} & \multicolumn{1}{c}{$y_{f}$} & \multicolumn{1}{c}{$y_{m}$} \\
\hline PK estimator & 0.996 & 0.998 & & 1.112 & 1.124 \\
& $(0.025)$ & $(0.025)$ & & $(0.030)$ & $(0.031)$ \\
Linear LIML & 0.996 & 0.990 & 0.990 & 1.008 \\
& $(0.046)$ & $(0.054)$ & $(0.050)$ & $(0.054)$ \\
\hline
\end{tabular}

True coefficients are I.0. Standard deviations in parentheses. 